\title{
HET TOBA-BATAKSCHE VERHAAL VAN SI TADJOM BOLAK EN SI RADJA MEBANGEBANG
}

\author{
DOOR
}

D. W. N. DE BOER.

(Met één facsimilé).

\section{Inleiding:}

In deze Bijdragen, deel 103 afl. 3/4, werden onder den titel: „Zeden, gewoonten en wetten van Nai Pospos” opgenomen een transcriptie en een vertaling van de blzz. 205-254 van Deel VIII der „Collectie van Bataksche Handschriften” ex legato H. Neubronner van der Tuuk, in de Leidsche Universiteitsbibliotheek te boek staande als Codex Orientalis No. 3405 (kastnummer $767 \mathrm{~h}$ van de MaleischPolynesische afdeeling).

Daarmede werd gecompleteerd de vertaling van het in de summiere inhoudsopgave van den verzamelaar dier Handschriften als $6^{\circ}$ van deel VIII aangegeven: „Zeden, gewoonten en wetten van die van Naie pospos", waarvan het gedeelte voorkomend op blzz. 254-280 reeds door Vergouwen vertaald werd en gepubliceerd in Adatrechtbundel XXXV (Serie G No. 64) blzz. 135-154.

Verder werd van genoemden Codex door Van der Tuuk zelf het ad $1^{\circ}$ genoemde stuk, „Soetan Malien Deèman”, een verhaal ook bekend uit de Maleische, Minangkabausche en Atjèhsche Hikajats van dien naam, uitgegeven in zijn Bataksch Leesboek, 1ste stuk, blzz. 87-201. Inhoudsopgaven van dezen tekst zijn gepubliceerd door Niemann, Pleyte en Warneck; een bespreking ervan heeft Voorhoeve gegeven in zijn proefschrift: Overzicht van de Volksverhalen der Bataks, blz. 132-134 (No. 115).

Dan werd nog vertaald het onder $7^{\circ}$ van Van der Tuuk's summiere inhoudsopgave genoemde: „Sie tapie boenga boroe” (blzz. 281-300), namelijk door Pleyte, volgens Voorhoeve met veel fouten, in deze Bijdragen, 7de volgreeks deel IV (blzz. 348-356). Zie Voorhoeve's korte inhoudsoverzicht hiervan op blz. 102 (No. 69) van zijn proefschrift. 
Van de overige nummers tenslotte (uitgezonderd het ad $4^{\circ}$ genoemde "Tonggotonggo", dat offerande-formulieren bevat) gaf Voorhoeve in genoemde dissertatie korte inhoudsoverzichten; t.w.: ad $2^{\circ}$ : ,Moela nie bodat die bahen na lan nannón”, in twee gedeelten: n.l. het gedeelte, dat de blzz. 101-107 van het Handschrift beslaat, op blz. 74 (No. 16), terwijl de blzz. 107-150 van het manuscript behandeld worden op blz. 160 (No. 162c) ; ad $3^{\circ}$ : „Radja Madiengien”: op blz. 187 (No. 218); ad $5^{\circ}$ : „Sie tadjom bolak”: op blz. 161 (No. 164).

Aangezien door Voorhoeve aan het onderwerp ad $5^{\circ}$ slechts 3 regels werden gewijd, waarbij hij zich bovendien in den naam van den eigenlijken, ,held van het verhaal” vergist, koos ik nu dit stuk voor transcriptie en vertaling.

De tekst van dit nummer was hier en daar moeilijk te ontcijferen door onduidelijk schrift, des te minder leesbaar gemaakt door vlekken en doorhalingen. Het bijgevoegde helder uitgevoerde facsimilé is van een der duidelijkste bladzijden (189). Zij werd dáárom uit de voor transcriptie en vertaling gemaakte photocopieën van dit stuk voor publicatie gekozen, omdat zij - als éérste pagina - de bindoefiguur draagt, in noot 1 op blz. 343 van Bijdragen deel 103 genoemd.

Dat er ook weleens een niet gecorrigeerd schrijffoutje voorkomt, zelfs op een zoo nette bladzijde als de hier gereproduceerde, kan blijken uit regel 18 van deze eerste pagina, waar door het ontbreiken van een sluitstreepje na de „o" geschreven staat: „oelasona” voor: „oelosna”.

Zooals bij de beschouwing van de photocopie verder kan blijken, wordt het lezen van dergelijke oud-Bataksche geschriften bovendien bemoeilijkt, doordat volgens de toenmalige Bataksche schrijfwijze de letters onafgebroken aan elkaar geregen zijn, terwijl aan het einde van den regel een woord willekeurig afgebroken wordt zooals dat toevallig met de ruimte uitvalt, zoodat de door agglutineering gevormde woorden vaak niet dadelijk gelezen kunnen worden.

In de transcriptie werden deze letterreeksen terwille van de leesbaarheid uiteraard in afzonderlijke door spatie van elkaar afgescheiden woorden gegroepeerd; terwijl mede van de noodige leesteekens zoomede hoofdletters gebruik werd gemaakt, en de tekst verder in alinea's werd ingedeeld.

Overigens is het handschrift letterlijk gevolgd. Daarbij zijn de door Van der Tuuk aangebrachte verbeteringen, bestaande in enkele ver- 


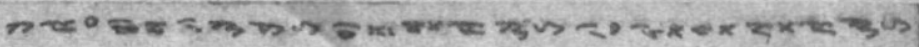

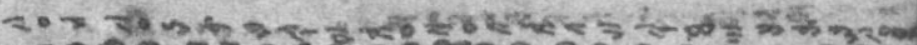

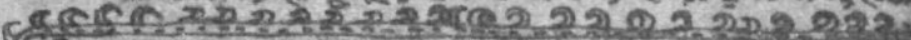

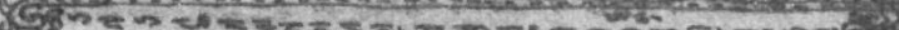
2.

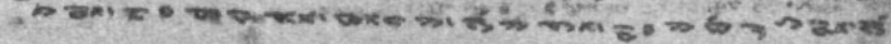

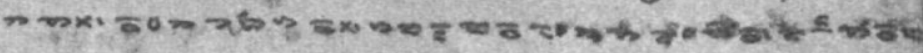
9.

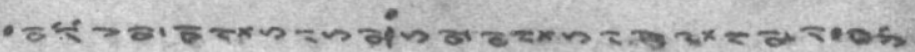
aा

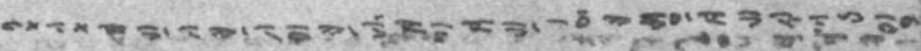

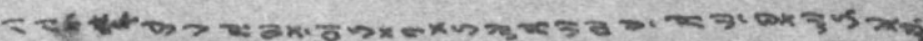
6rite

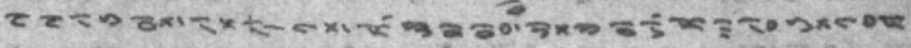
20.0.

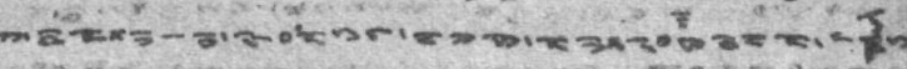

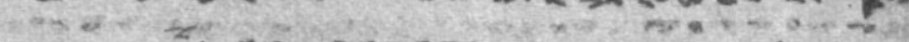

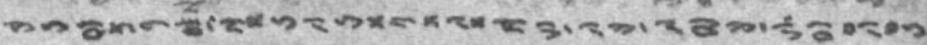

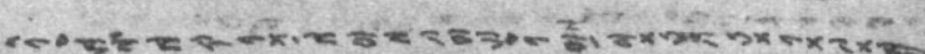

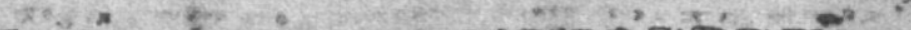

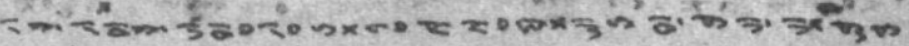
C.

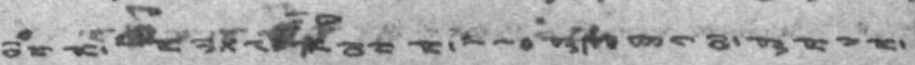

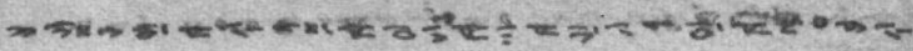

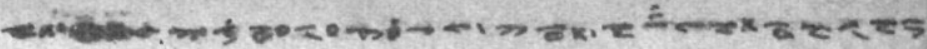
mon

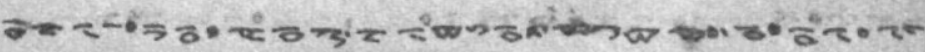

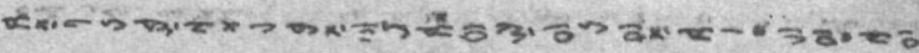

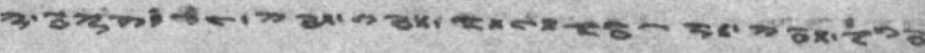

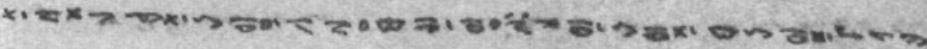

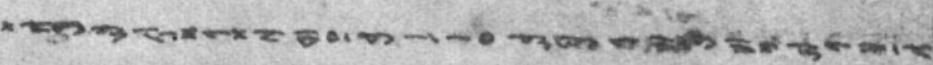

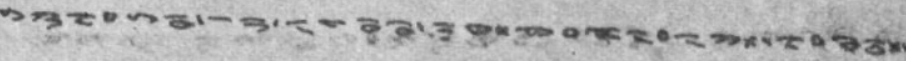

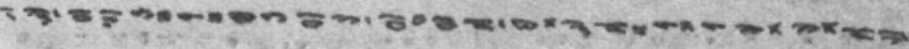

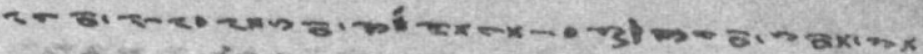
(N)

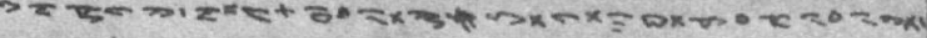

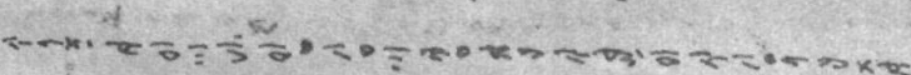

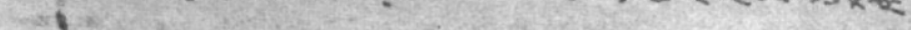

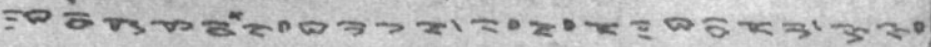

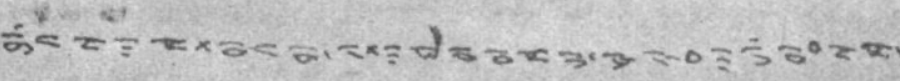

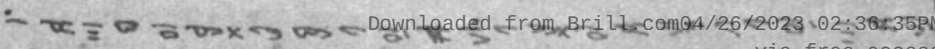

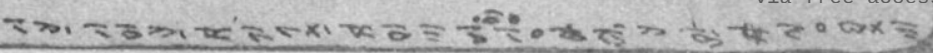


duidelijkende toevoegingen en kleine wijzigingen in de spelling, overgenomen, waar noodig met een toelichting in de aanteekeningen. Dit uniformeeren van de spelling is door Van der Tuuk niet voltooid, vandaar dat men de sub-Tobasche vormen van den schrijver nu eens in Tobasche veranderd vindt (bijv. dibeangkon voor dibajangkon), dan weer niet.

Konden de moeilijkheden van het schrift worden overwonnen, moeilijker was het, om voor de diverse familiebetrekkingen en aanspreek-titels een passende Nederlandsche vertaling te vinden; voor de bijzondere persoonlijke verhoudingen, die in de Bataksche titels opgesloten liggen, bestaan nu eenmaal geen Nederlandsche begrippen. Voorzoover noodig, werden de bijzonderheden van die verhoudingen in nooten aangegeven.

Wat tenslotte de stijl van de vertaling betreft, moet ik alweer de clementie van de lezers inroepen, waar terwille van meer soepelheid dan reeds door mij nagestreefd, taalkundig te veel van den origineelen tekst zou moeten worden afgeweken. Men leze in dit verband hetgeen Voorhoeve (deel 92 van deze Bijdragen, blz. 213) schrijft in zijn Inleiding tot de vertaling door Prof. Mr. Dr. J. C. G. Jonker van eenige Soembawareesche teksten.

En hier volgt dan het verhaal in transcriptie en vertaling.

\section{Transcriptie.}

p. 189 Asa adong ma nasaingan hata ni soehoetan na margoarhon $\mathrm{Si}$ Tadjom Bolak, soengkot ni habegoeon soengkot ni hagabeon; asa $\mathrm{i}$ ma na di Hoeta Silense Oetang, na mardjolmahon Si Tondja di Portibi, soengkot ni hinadenggan, na soada anian, na soada toedosan dibahen hinadengganna. Doeng ni sampe ma sataon las soada olo do mardakdanak. Doeng ma i marpingkir ma Radja i: „Indadong tagamon na olo ahoe maranak marboroe, anggo toeng sasada on do djolmangkoe!" ninna rohana. Doeng ma i dioli ma Si Boroe Nan Sarindan toe Hoeta Torop, boroe ni halak Namora Pandji Meal. Sahat ma ro di ibana sampe doea taon, las soada olo do mardakdanak. Doeng ni dioli moese ma djolmana sadanari, las soada olo do mardakdanak. Doeng ni dioli ma Si Boroe Antar Roha toe tano Loemban Si Odjak, boroe ni Radja Tinoempak. Doeng ni sampe ma ro di ibana, sampe pitoe boelan, toemagam haroan ma djolmana. 
Doeng ma i mardalan ma Si Tadjom Bolak. Doeng ni ditinggalhon ma oelosna sada, saraoalna sada, badjoebadjoena sada, tintinna sada, podangna sada, pira ni manoek sada. „Ba, on ma abit ni na di dalom laoet, sogot! ia manoekna : on ma, pira ni manoek na hoetinggalhon on! Molo manapor honsa on sogot, inda sibar ni denggan on! $\mathrm{Ba}$, on pe laho ma ahoe djolo, sintap pitoe boelan on moelak ma ahoe sian pardalanan i!" boti ma didok sinondoekna i. „Olo ba, anak ni namboroe; molo laho ho mardalan, djadi do antong! Molo pitoe boelan on ho asa moelak, songon i do hoeoloi!" boti ma didok djolmana i. Doeng ni diisi ma hadjoetna, djadi laho ma ibana toe tano Si Baragas; disi ma ibana mardjoedji. Noengnga sai monangan do ibana na mardjoedji i.

Doeng ni sampe ma ibana toloe boelan doeng laho na mordalan i, mardakdanak ma djolmana i. Doeng ni disoengkoen Si Boroe Antar p. 190 Roha ma imbangna i: „Beha do roehoet ni pardakdanahon, ale hahang?” boti ma didok Si Boroe Antar Roha. „Olo ba, anggi! anggo roehoet ni pardakdanahon na hoeida hami: disoempol do pinggolna, ditoetoep do matana, diihoti do tanganna, i ma roehoet ni pardakdanahon, anggo na hoeida hami!" boti ma didok imbangna sitoloe halak i. „Olo ba, hahang! molo songon i ma roehoet ni pardakdanahon diida hamoe, patoepa hamoe ma di ahoe, tole ma rohangkoe tolhas haroanta!" boti ma didok Si Boroe Antar Roha. Djadi toetoe disoempol ma pinggolna, ditoetoep ma matana, diihoti ma tanganna. Doeng ma i tolhas ma haroan, sada lahilahi, sada boroeboroe. Doeng ni ro ma imbangna sitoloe halak $i$, dipabongkot ma na toeboe $i$ toe bogasan ampang; dibahen ma dohot oelos tininggalhon ni Si Tadjom Bolak dohot pira ni manoek i. Doeng ni dioembang ma toe aek na bolon: „Maoep, maoep, damang Radja Mebangebang! noengnga ro disi oelos na tinadingkon ni amam dohot pira ni manoek na tinadingkon ni amam!' boti ma didok nasida. Djadi toetoe maoep ma halak i.

Doeng indadong be tarida di nasida, laho ma nasida moeli, disingkathon ma harpe dohot sipoesipoe toe djolo ni Si Antar Roha; doeng ni diharhari ma panoetoep ni matana $i$, diharhari ma pangihoti ni tanganna i, diboeat ma panoempol ni pinggolna i. Doeng ni dibereng Si Antar Roha ma toe djolona, diida harpe dohot sipoesipoe, doeng ni disoengkoen ma imbangna: „Ba, dia do, ale hahang, na hoetoeboehon i?” boti ma ninna. Doeng ni dibalos imbangna i: „Toetoe, 
beasa ma manoengkoen ho di hami? boroe ni asoe, boeragan ho so marbortian! Harpe do dohot sipoesipoe ditoeboehon ho! Anggo apala p. 191 mangan ho, indadong djadi! boroe ni asoe, boroe ni bodat!" boti ma didok imbangna i. Doeng ni ditoendjangi nasida na toloe ma Si Boroe Antar Roha. Doeng ni sai toematangis ma ibana ganoep ari ganoep borngin.

Doeng ni sahat ma ampang i ro di tapian ni halak Datoe Arang ni Begoe. Doeng ma i toe aek ma djolmana Si Tadjo Barang Holboeng; diida ma ampang i noengnga sai hoemationghationg di tapianna $i$, sai naeng ditangkoep nian, indadong dapotsa. Doeng ni maoep moesengani ma Si Radja Mebangebang dohot ibotona i Si Boroe Ramiramian sian i. Ro ma sigak, dibongkoti ma toe bogasan ampang $i$, doeng ni sai dipamboeat sigak ma goebogoebo, i ma dipammemehon toe $\mathrm{Si}$ Radja Mebangebang dohot toe Si Boroe Ramiramian. Doeng ni godanggodang ansimoen ma nasida na doea.

Doeng ni laho ma Si Radja Mebangebang masihotang (sihotang) toe harangan; djoempasa ma anak ni babiat, ditangkoep ma toetoe. Doeng ni diboan toe soposoponasida i. Doeng ni sai dipahanpahan ma babiat $i$; noengnga magodang.

Doeng ni ro ma sigak: „Boti ma i, pahompoe hasian Radja Mebangebang! tama hita djolo toe hoeta ni inam Nan Djoenggele di Portibi, asa itapangido djolo bodil Patanda Radja pinaloemehon ni amam $\mathrm{Si}$ Tadjom Bolak dohot balioeng dohot tangke dohot rimbas dohot toehil dohot rabi dohot sigirik, asa paoeli paraoe ho djolo, asa adong dalanta moelak laho manopot inanta Si Boroe Antar Roha".

Doeng ni laho ma nasida toe hoeta ni Nan Djoenggele di Portibi. Doeng ni bongkot ma nasida. Doeng ni ditopot ma toe bagas ni inana $\mathrm{i}$; hoendoel ma ibana toe lamboeng ni inana $\mathrm{i}$. Doeng ni disoerdoekkon ma hadjoetna: „Marnapoeran ma ho ale inangoeda!” boti ma didok Si Radja Mebangebang. Doeng ni tarhalomong ma inana $\mathrm{i}$ : „Ai ise ho damang, dibahen inangoedam didok ho ahoe?" boti ma didok Nan Djoenggele di Portibi. „Olo ba, inang! dibahen na inangoeda pe p. 192 ningkoe dompak ho, dibahen nadong do halak mandok anggi ni inantanami ho ninna halak!" boti ma didok Si Radja Mebangebang. „Olo ba, amang! molo anak ni dahahang ma, Si Antar Roha ma, ho, djadi do toetoe; aha ma nioela ni damang toe hoeta on?" boti ma

D1. 104. 
didok inangoedana i. „Olo ba, inang! ro pe ahoe toe hoeta on mangalap sipaloemean ni damang Si Tadjom Bolak, i do na hoeoela toe hoeta on!" boti ma didok Si Radja Mebangebang. „Olo, amang! molo i ma nialap ni damang, toetoe do $\mathrm{i}$ antong; hoendoelhoendoel ma damang djolo, mangalompa ma ahoe!" boti ma didok inana i. Djadi mangalompa ma ibana; doeng masak, disondoek ma toe panganan, dibahen ma parboerian, dilehon ma toe anakna i. Djadi mangan ma anakna i. Doeng ni soen ma na mangan i, dihandit ma panganan i. Doeng ni disoerdoekkon ma handoengan; marnapoeran ma Si Radja Mebangebang. Soen marnapoeran, dipaoelak ma handoengan i. Doeng ni dilehon ma lage, laho ma anakna i modom. Torang ni arina diboeat sada babi panganon ni anakna i; doeng soen masak, dipiohon mansipanganon. Soen mansipanganon, dipaoelak ma toetoe sipaloemean i saloehoetna. Doeng ni moelak ma anakna i: „Laho ahoe djolo, ale inangoeda!” boti ma ninna. „Olo ba, amang!" ninna inana i. Djadi laho ma ibana. Doeng ni sahat ma ro di soposoponasida i.

Doeng sampe nasida pitoe taon doeng honsa nioembang ni inana siopat halak, moelak ma Si Tadjom Bolak sian pardalanan i. Noengnga boratan naposona marboan mas, hatobanna diboan saratoes doea poeloe na dapot di djoedji horing. Doeng sahat ma ibana ro di hoeta, didapot ma halak Si Boroe Antar Roha noengnga sai margoendompong do di ingananna i. Doeng ni ditaroei naposona i ma arta na binoanna i. Doeng ni disoengkoen Radja i ma djolmana i: ,Toe dia do dakdanakta i dibahen ho? ai noengnga matoras eme hoetingp. 193 galhon! noengnga sagala pitoe taon ahoe! beha ma? inda noengnga magodang i?” boti ma didok sinondoekna i. „Olo ba, anak ni namboroe, anggo na nidokmi, tongon do $i$, alai ale anak ni namboroe, soemalin do paroentoengan sian halak, ai toeng harpe do ninna dahahang siopat halak hoetoeboehon dohot sipoesipoe", boti ma ninna djolmana i. "Olo boroe ni Radjanami! molo i do ditoeboehon ho, moelak ma ho toe hoelahoelam! Toeng mambahen tihas ho di ahoe!" boti ma ninna. „Olo anak ni Radjanami! molo apala paoelahonmoe ma ahoe sabat ni, djadi do antong! Alai hatanasida do! atik toeng djolma pe na hoetoeboehon! soada hoeida, soada hoebege, soada hoedjama! Ia hoesoengkoen di nasida roehoet ni pardakdanahon, soempolon do ninna pinggol, toetoepon ninna mata, ihotan ninna tangan. Asa diihoti nasida do tanganhoe, disoempol do pinggolhoe, ditoetoep do matangkoe!" boti ma didok djolmana i. „Olo ba, boroe ni datoelang! molo songon $\mathrm{i}$, oenang ho hoepaoelak, alai hoeporsoek 
ma ho anggo intap sataon on!" boti ma didok Radja i. Doeng ni dipailing ma arta pineop ni djolmana $\mathrm{i}$, dilehon ma toe djolmana siopat halak i. Doeng ni laho ma ibana modom, di inganan ni djolma na sada i ma ibana modom. Torang ni arina disarat ma sian bagas Si Boroe Antar Roha toe toroe, dibajangkon ma toe sopo.

Doeng ni ro ma sigak, ditingkir ma toe hoeta i, diida ma Si Boroe Antar Roha toe sopo, noengnga sai martoetoengkian do ibana. Doeng ni moelak ma sigak i toe soposoponasida i, dipaboa ma toe Si Radja Mebangebang: „Noengnga dibajangkon di sopo na balga i inanta!” boti ma didok sigak. „Olo ba, ompoeng! molo noengnga dibajangkon inanta $i$, beha bahenon? ditaonton djolo na porsoek $i$; molo mandokkon tondi sogot, atik marbalos do na loengoen!" boti ma didok Si Radja Mebangebang.

Doeng ni laho ma ibana mambahen paraoe. Doeng ni ditaba ma haoe piras; maroempak ma haoe $\mathrm{i}$; doeng ni marsoeraksoerak ma pidong rikrik dibege sigak. Doeng ni mandjooe ma ibana : „Gagaoak! na beha do ho ale Radja Mebangebang?" boti ma didok sigak. Ro ma Si Radja Mebangebang: "Dison do ahoe, da ba ompoeng! inda p. 194 toeng ditinggang haoe na hoetaba $\mathrm{i}$ ahoe!” boti ma ninna. „Olo ba, pahompoe hasian! molo noengnga songon $i$ hoebege soaram, noengnga pos rohangkoe!" ninna sigak. Doeng ni disoepak ma gandjang ni paraoena i, dibahen ma siopat holak gandjang ni paraoena i. Doeng ni dipaoeli ma toetoe; sampe pitoe ari dipaoeli, soen ma dibahen. Doeng ni didiang ma paraoena $i$, doeng ni diboan ma toe soponasida $i$.

Doeng sampe pitoe borngin laho ma ibana toe hoeta ni Namora Toenggoel. Sahat ro di tapian ni Namora Toenggoel, dipaloe ma bodilna i, tahoeak manoekna manoek Patea Radja, marngaoeng ma babiat Si Bolang. Doeng ni marlodjongi ma partoeaek laho toe hoeta. Doeng ni manoengkoen ma Namora Toenggoel: „Beasa marlodjongi hamoena partoeaek i? aha na masa disi ?” boti ma didok Radja ni hoeta i. „Olo, Radjanami, marlodjongi pe hami dibahen nadong do parparaoe ro di tapian an, mamodil ibana, marngaoeng babiatna, tahoeak manoekna!" boti ma didok partoeaek i. Djadi marhobas ma Radja i, diarahon ma naposona, ditingkir ma toe tapian i, diida ma toetoe paraoe i. Doeng ni disoengkoen ma: „Ise ma hamoe na di paraoe $i$, mamodil hamoe, marngaoeng babiatmoe, tahoeak manoekmoe, dohot parompoean i soendat manoehoel hionghiong!?" boti ma 
didok Radja i. „Olo ba, Radjanami! hami do i, toetoe mamodil ahoe, marngaoeng toetoe babiathoe, tahoeak manoekkoe; ia ì do, donganhoe di paraoe on, inda i mangkoeling !" boti ma didok Si Radja Mebangebang. „Molo songon $i$, aha ma nioelam dibahen na ro toe hoetanta on?” boti ma didok Radja i. „Olo, Radjanami! ro pe ahoe toeson dibahen na hoebege do barita ni panaboengon di hoeta on inda na hapalang ni riboer; $\mathrm{i}$ do na hoetopot, dibahen ahoe na ro!" boti ma didok. „Olo, Radjanami! molo i ma nioela ni damang dibahen na ro, marsogot pe hita manaboeng, anggo nannon modom be ma djolo hita!' boti ma didok Namora Toenggoel. Doeng ni moeli ibana toe hoeta, didokkon ma boroeboroe $\mathrm{i}$ toe aek: „Laho ma ho toe aek! p. 195 indadong mangago i babiat ni na ro i!" boti ma didok Radja i. Djadi laho ma toetoe na toe aek i. Doeng ni torang ni arina borhat ma Namora Toenggoel, diboan ma manoekna manoek Hoealam Radja, manoek gonggom-sahoeta, diboan ma taroena sariboe opat ratoes. Doeng ni laho ma ibana toe tapianna i; doeng ni didjooe ma Si Radja Mebangebang: „,Tole ma Radjanami na manaboeng on!” boti ma didok Radja i. „Olo, Radjanami! tole ma hita toetoe !” boti ma didok Si Radja Mebangebang. Djadi roear ma ibana sian paraoena i, diboelang ma manoekna i. Doeng ni diboelang Namora Toenggoel ma manoekna i. Doeng ni martaroe ma nasida sariboe opat ratoes be. Doeng ni disaboeng ma manoeknasida i, santandak do dibahen manoek ni Si Radja Mebangebang, noengnga taloe Namora Toenggoel, ai pintor mate do manoekna i. Doeng ma i dipainding ma arta i, dipambahen ma toe paraoena i.

Doeng ni laho ma nasida toe hoeta ni Porhas Manoro. Sahat ma ro di tapianna $i$, dipaloe ma bodil Patanda Radja, marngaoeng ma babiatna i, tahoeak manoekna i. Goentoer ma na sian hoeta marlodjongi toe tapian i. Doeng ni diida ma paraoe ni Radja i di tapian i. Doeng ni disoengkoen na maningkir i ma toetoe: „Ise ma hamoe na mamodil i, djana mangkoeling babiatmoe, tahoeak manoekmoe? $\mathrm{Na}$ laon ma na lolot, indadong doeng songon i halak ro toe tapian on!" Boti ma didok na maningkir i. „Olo, Radjanami! toeng mangkoeling pe bodilhi, tahoeak manoekki, dohot babiathi, inda toeng na olo i mangago djolma dohot pinahan!" boti ma didok Si Radja Mebangebang. „Olo, Radjanami! ba, ia aha ma nioelamoe dibahen na ro toe tapian on?” boti ma ninna na maningkir i. „Olo amang! ro pe ahoe toeson, dibahen na hoebege do barita ni saboeng di hoeta on, indada na bolakna, i do na hoetingkir toe hoeta on!" boti ma ninna sian 
paraoena i. „Olo, Radjanami, molo i do nioelamoe dibahen na ro, marsogot pe hita manaboeng! Laho ma hami moelak toe hoeta!' ba, i ma ninna na maningkir i. Doeng ni laho ma nasida toe hoeta. Doeng ni disoengkoen Radja i ma na maningkir i: „Ise do na mamodil di tapian i?” boti ma didok Porhas Manoro. „Olo, Radjanami! Si Radja Mebangebang do na ro i naeng manaboeng ninna ibana!" boti ma didok na maningkir i. „Molo songon i didok na ro $i$, denggan ma $i$ antong!" boti ma didok Radja i. Doeng ni mangan be ma nasida.

p. 196 Torang ni arina, marhobas ma ibana, didongkon ma diboan naposona i mas toloe poti, diboeat Radja i ma paheanna, doeng ni laho ma nasida, diboan manoekna manoek Hoeaso Padang. Doeng sahat nasida ro di tapian i, didjooe ma Si Radja Mebangebang: „Tole ma 'le Radjanami, na manaboeng on!' boti ma didok Porhas Manoro. „Olo, Radjanami! ro ma ahoe antong! ai aha hian na hoeoela dibahen na ro toeson inda na naeng manaboeng!" boti ma didok Si Radja Mebangebang. Djadi diboelang nasida be ma manoekna i. Doeng soen tarboelang manoek i, disaboeng ma toetoe: santandak do dibahen manoek ni Radja Mebangebang, noengnga mate manoek ni Porhas Manoro. Doeng ni dihanditi ma poti i, dipampei toe paraoena i. Doeng ni mangkoeling ma Radja Porhas Manoro: „Boti ma i, Radja Mebangebang! oenang laho ho djolo, naeng itaoelahi manaboeng marsogot!' boti ma didok Porhas Manoro. Doeng ni laho ma nasida toe hoeta.

Torang ni arina diboa [n] ma manoekna. Doeng ni sahat ma ibana ro di tapian i, diboelang nasida be ma manoeknasida i. Doeng ma i martaroe ma nasida, didok Porhas Manoro ma taroena hatobanna toloe, boroena sada, ogoengna toloe rabanan. „Molo taloe ahoe dibahen ho, di ho ma $\mathrm{i}$ saloehoet na hoedok $\mathrm{i}$, bahen djolmam ma boroengki, alai inda toeng hatoban i dohononmoe!" boti ma didok Porhas Manoro. Doeng ni tole ma nasida manaboeng; taloe ma Porhas Manoro. Doeng ni : „Alap ma boroemoena i dohot hatobanmoena i!” boti ma didok Si Radja Mebangebang. Doeng ni dialap ma toetoe boroena i dohot hatoban i. „Beta ma, inang Boroe Sori Naek! hoepasahat do inang toe sinondoekmoe!" boti ma didok Si Porhas Manoro. „Olo ba, apang! toe sinondoekkoe ma ahoe hape, ai ise helami da ba apang ?" boti ma didok boroena i. Doeng ni dipaboa ma toetoe: „Si Radja Mebangebang ma sinondoekmi!" boti ma didok amana i. „Olo ba, apang! molo i ma hape sinondoekki, djadi do, ale apang!" boti ma 
didok boroena i. Djadi diboan ma boroena i, diboan ogoeng toloe rabanan, hatoban toloe, dilehon ma toe Si Radja Mebangebang: „On ma boroengki, ale amang hela!” boti ma didok Porhas Manoro. „Olo, simatoeangkoe!" ninna Radja i. Doeng ni dipabongkot ma toe paraoena i. Doeng ni moelak ma nasida.

Tole mandapothon soponasida $i$, mamodil ma ibana. Dibege sigak, mangkoeling ma ibana: „Gagaoak! beha do panaboengon, ale p. 197 Radja Mebangebang?” boti ma didok sigak. „Olo ba, ompoeng! monang do ahoe, noengnga dapot ahoe sada na denggan, boroeboroe, bahen djolmangkoe ma i di soposoponta on!" boti ma didok Si Radja Mebangebang. Djadi bongkot ma ibana toe bogasan sopo i. Doeng ni didongkon naposona i mandjagai paraoenasida $\mathrm{i}$ dohot ogoeng $\mathrm{i}$. Doeng ni mangalompa ma nasida; soen mangalompa, asa mangan ma nasida. Doeng ni modom ma nasida, rap ma nasida dohot $\mathrm{Si}$ Boroe Sori Naek. Doeng torang ari, dilompa ma indahan dohot dengke. Doeng soen masak, mangan ma nasida; soen mangan diparait ma ogoengna $i$; noengnga sai maraloenaloen do soara ni ogoengna $i$. Doeng ni mansohot ma nasida na mangogoeng $i$, dipaoelak ma toe paraoena i.

Doeng ni marpingkir ma roha ni halak Si Radja Mebangebang: „Moelak ma ahoe toe hoetanami, noengnga malam mate inantanami di bajangan!" ninna rohana. Doeng ni sampe pitoe borngin marhobas ma ibana. „Laho ma hita ompoeng toe hoeta ni amanta, malam mate ma inanta na binajangkon ni amanta i!" boti ma didok Si Radja Mebangebang. „Olo ba, ompoeng! molo laho ma hita, djadi ma toetoe!" boti ma didok sigak. Djadi laho ma nasida; diborsihon ma paraoena i.

Doeng sahat ma nasida ro di tapian ni Si Djangga Moera Meroe, mamodil ma ibana, marngaoeng babiatna $i$, tahoeak manoekna $i$. Goentoer ma sian hoeta, ro ma toe tapian i, disoengkoen ma nasida na di paraoe i: „Ise ma hamoe na mamodil i? $\mathrm{Na}$ laon ma na lolot indadong doeng ro toe tapiannami on songon $\mathrm{i}$, mangkoeling bodilna, marngaoeng babiatna, tahoeak manoekna!' boti ma didok na maningkir i. Doeng ni dibalos Si Radja Mebangebang ma toetoe: „Olo, Radjanami! mangkoeling pe bodilhi, tahoeak manoekki, marngaoeng babiathi, inda toeng na mangago i di djolma dohot di pinahan!" boti ma didok Si Radja Mebangebang. „Olo ba, Radjanami! ba, aha ma 
nioelam dibahen apala ro toe tapianta on ?" boti ma didok na maningkir i. „Olo ba, amang! ro pe ahoe toe tapianmoena on, na manandangkon panaboengon do ahoe!” boti ma ninna Radja i. „Molo i do tinandangkonmoe toe banoea on, hoepaboa hami djolo toe Radja i, atik aloonna do hamoe!" boti ma didok na maningkir i. Djadi moelak p. 198 ma nasida toe hoeta. Doeng ma i manoengkoen ma Radja i: „Ise do na mamodil di tapian i ?” boti ma didok Radja i. „Olo ba, Radjanami! Si Radja Mebangebang do na ro i toemandangkon saboeng, ninna ibana!” boti ma didok na maningkir i. „Olo ba, molo i ma nioelana, djadi do antong! paboa hamoe ne di ibana: marsogot pe, ninna Radja i, hamoe manaboeng, i ma dok hamoe!" boti ma didok Radja i. „Olo!" ninna nasida; djadi moelak ma nasida toe tapian $i$, didjooe ma Radja i: „Boti ma i, Radjanami Radja Mebangebang! oenang toeng laho ho, ninna Radja i, marsogot pe hamoe manaboeng, ninna Radja i!" boti ma didok na maningkir i. „Olo, amang, molo marsogot ninna Radja i sian hoeta manaboeng hami, djadi do antong!" boti ma didok Si Radja Mebangebang. Djadi moelak ma nasida toe hoeta. Doeng ni modom be ma nasida.

Doeng torang ari, marhobas ma Radja i, didongkon ma naposona marboan poti. Doeng ni tole ma disaboeng manoeknasida $i$, taloe ma Radja Si Djangga Moera Meroe. Djadi ditaroei ma hamonangan i toe paraoena $i$.

Doeng ni laho ma nasida toe hoeta ni namboroena. Disi ro di tapian ni namboroena $i$, diborothon ma paraoena $i$, dipaloe ma bodilna $i$, mangkoeling babiatna $i$, tahoeak manoekna i. Doeng ni marlodjong ma namboroena i sian hoeta: „Ise ma hamoe na mamodil, na di tapian on?” boti ma ninna. Ro ma sigak: ,Tanda ma roepana, Boroe Boenga Pandan Matogoe! Tarbarita ma ho paralamat pandang toroes! Alamat ma djolo!” boti ma didok sigak. „Olo ba, ompoeng! anggo hata ni alamathon hoeida roepa anak ni ibotongkoe do on, Si Radja Mebangebang ninna goarna; djolmana ninna boroeboroe sada on, Si Boroe Sori Naek ninna goarna; ia boroeboroe sada on paroemaenhoe do on, Si Boroe Ramiramian goarna!" boti ma didok Si Boroe Boenga Pandan Matogoe. Doeng ni pintor dihaol Si Radja Mebangebang ma namboroena i. „Ola ba, namboroe! besi ma hita toe hoeta! alai, molo ro amanta sian hoeta an, so toeng dipaboa ho ahoe! Anggo p. 199 indadong sidegedegeanhoe djolmana na opat halak dohot sidegean ni inanta $\mathrm{i}$ dohot sidegean ni paroemaenmon, lan soada olo do ahoe toe 
hoetana i!” boti ma didok Si Radja Mebangebang. „Olo ba, apang! oea oenang didok ho $i$, inda hoeboto do $i$ ?" boti ma didok namboroena i. Doeng ni moeli ma nasida toe hoeta. Sahat ro di hoeta, dipaloe ma bodilna $i$, marngaoeng ma babiatna $i$, tahoeak ma manoekna $i$. Noengnga soede halak longang marnida babiatna i. Doeng ni ditaroei ma toe bagas oegasanna i saloehoetna. Doeng ni mangan ma nasida. Soen mangan, didatdati nasida ma mamodili.

Ro ma roha ni halak Si Tadjom Bolak: „Aha ma na masa oelaning di hoeta ni ibotongkan, dibahen sai mamodili?" ninna rohana. Doeng ni torang ni arina didongkon ma hoematop djolmana i mangalompa. Doeng soen masak, mangan ma ibana; soen mangan, marhobas ma ibana, laho ma toe hoeta ni ibotona i, mandoelo ma ibana di harbangan, dipaloe naposo ni Si Radja Mebangebang ma bodil i. Doeng ni manoengkoen ma Radja i : ,Aha na masa di hoeta on dibahen mamodili hamoe?” boti ma didok Radja i. „Olo, Radjanami, mamodili pe hami dibahen nadong do ro na bodari tamoeë ni Radja i, borat paraoena, marboan ma dohot ogoeng dohot hatoban!" boti ma didok namora ni hoeta i. Ro ma pamalos ni Radja i: „Ai halak sian hoeta dia leatni na ro $i$ ?” boti ma ninna. „Indadong hoeboto, barang sian hoeta dia!" boti ma didok namora i.

Doeng ni laho ma Si Tadjom Bolak toe bagas, dipasolhot ma toe lamboeng ni ibotona i. Doeng ni disoerdoengkon Si Radja Mebangebang ma hadjoetna: „Marnapoeran ho ale Radjanami!” boti ma didok. „Olo, Radjanami! molo dilehon dongan-Radja iba marnapoeran, djaloon do antong! alai anggo hadjoethoe indadong marisi!" boti ma didok Radja i. „Olo, Radjanami, molo soada adong, toeng na masisambaran!" boti ma didok Si Radja Mebangebang. Doeng ni marnapoeran ma Si Tadjom Bolak. Soen marnapoeran, dipaoelak ma hadjoet i. Doeng ni disoengkoen Radja i ma Si Radja Mebangebang: „Na sian hoeta dia ma hamoe?” boti ma ninna [Si] Tadjom

p. 200 Bolak. „Olo ba, Radjanami, indadong na hoeboto dohononhoe goar ni hoetanami, adong didok halak Tombak Siharangan, i ma goar ni hoetanami!" boti ma ninna. „Olo, molo i ma goar ni hoetamoe!” boti ma didok Radja i. „Olo, Radjanami, ianggo goar ni amantanami dohot inantanami indadong hoeboto; ai disi do ahoe toeboe, pintor mate do amanta dohot inanta!" boti ma didok Si Radja Mebangebang.

Doeng ni disoengkoen Radja i ma ibotona i: „Atehe itong, ise do i? hoeida oelosna $i$ songon oelos na hoeboeat do i, hoeida saraoalna $i$ 
dohot hohosna i dohot badjoebadjoena i dohot detarna i!" boti ma didok Radja i.

„Indada, itong, ianangkonhoe do i! Anggo oegasan na nidokmi atik na tanda saroepa i noeangin!" boti ma didok Si Boroe Boenga Pandan Matogoe. Doeng ni mansohot ma nasida ma mangkatai. „Laho ma ahoe moelak djolo, itong! marsogot pe ahoe ro, sai hoepatangkas do i di ho!" boti ma didok Radja i. „Olo ba, itong!” ninna ibotona i. Doeng ni laho ma ibana.

Sahat ma ro di hoeta, manoengkoen ma djolmana siopat halak: „Ise do na ro toe hoeta ni ibotonta i dibahen sai mamodili ?" boti ma didok djolmana i. „Indadong hoeboto tangkas; ia hoesoengkoen goar ni hoetana, Tombak Siharangan do ninna goarna; ia hoesoengkoen goar ni amana dohot goar ni inana, indadong diboto; disi toeboe do, ninna, ibana, pintor mate do ninna inana dohot amana. Ia hoeida oegasanna, songon oelos na hoetinggal do hoeida; ia hoesoengkoen goarna, $\mathrm{Si}$ Radja Mebangebang ninna goarna!" boti ma didok sinondoekna i. Doeng ni masiberengan ma boroeboroe na opat i. „Na hoeoembang hami na djoloan ma i!" sama ninna rohanasida ma di bogasan. Doeng ni laho ma toe toroe Radja i, ditanggal ma halak Si Boroe Antar p. 201 Roha sian bajangan i. „Noengnga mahap roham leatni na mame(j)angkon ahoe i!" boti ma didok djolmana i. „Olo toetoe, paboa na mambahen tihas ho di ahoe noengnga sataon manirsir ho hoebeangkon!" boti ma didok Radja i. Doeng ni laho ma djolmana i maridi, dioesai ma dahina i. Doeng soen ibana maridi, moeli ma ibana toe hoeta.

Doeng torang ni arina diboeat Radja i ma babi bahen oepaoepa ni djolmana i. Doeng ni laho ma ibana moese toe hoeta ni ibotona i. Doeng ni disoengkoen ma Si Radja Mebangebang: „Aha ma tinandangkonmoe toe hoeta on dibahen apala ro?" boti ma didok Radja i. „Olo, Radjanami! ro pe ahoe toe hoeta on, na manandangkon panaboengon do ahoe!" boti ma didok anakna i. "Molo songon i, tole ma hita manaboeng!" boti ma didok Radja i. "Olo ma toetoe!" ninna anakna i. Djadi manaboeng ma nasida, dihata ma taroenasida toloe riboe be. Taloe ma Radja i. Doeng ni didokkon ma naposona mangalap, dioelahi nasida ma manaboeng; sai taloe do Radja i. „Boti ma i, Radja Mebangebang, oenang toeng laho ho djolo! Moelak ahoe djolo toe hoetangkoe, marsogot pe itaoelahi manaboeng!" boti ma didok Radja i. „Olo, Radjanami! barang andigan nimmoe haroromoe manaboeng, sai na hoepaima do ho!" boti ma didok anakna i. Djadi laho 
ma ibana. Sahat ro di hoeta, manoengkoen ma djolmana siopat halak $i$ : „Beha do djoedji, anak ni namboroe?” boti ma didok djolmana $i$. „Olo ba, boroe ni datoelang! Noengnga taloe ahoe manaboeng dibahen tamoeë ni ibotonta $\mathrm{i}$; marsogot oelangkonongkoe dape manaboeng!" bóti ma didok Radja i.

Doeng ma i torang ni arina, diboeat ma manoek Mira Sialtong bahen patoengna. Doeng ni mangan ma ibana, disahadathon ma toe tondina: ,Ale tondingkoe! bege hatangkon! nantoari doea hali [ma]go ahoe manaboeng, sai taloe do ahoe $i$; nannon na patoloehalihon ma ahoe, ba, sai monang ma ahoe, ale tondingkoe!' boti ma didok Radja i. Djadi mangan ma ibana. Doeng soen mangan, diisi djolmana i ma hadjoet ni sinondoekna i. Doeng ni diarahon ma naposona, laho ma nasida, diboan ma poti toloe bahen taroena. Doeng ni diboan ma p. 202 tarapang sada, ponding sada, laho ma nasida.

Sahat ro di hoeta ni ibotona i: „Tole ma na manaboeng on, ale Radja Mebangebang!” boti ma didok Radja i. „Olo ma Radjanami!” ninna anakna i. Doeng ni manaboeng ma nasida; sai taloe do Radja i.

Doeng ni manaek ma ibana toe bagas ni ibotona i. „Beasa ho manaek toe bagas on? Noengnga beha djoedjimoena?" boti ma didok $\mathrm{Si}$ Boroe Boenga Pandan Matogoe. „Olo ba itong, noengnga taloe ahoe dibahen!' boti ma didok Radja i. „Molo noengnga taloe ho dibahen, dia do pingkir di rohamoe, asa di hamoena arta i ?" ba i ma ninna ibotona i. „Dia ma hoeboto pingkir!” ninna Radja i. „Oë, da ba itong! toeng dibajangkon hamoe pe Si Antar Roha, inda toeng harpe dohot sipoesipoe ditoeboehon, late ni roha ni siopat halak do, mangabing anak dohot boroe edangki, na dioembang do tinoeboehon ni edangki! „on ma oelos tinadingkon ni amam dohot pira ni manoek, ale Radja Mebangebang dohot ho ale Boroe Ramiramian!" na boti do na hinan dibahen djolmam siopat halak. On pe da ba itong, molo olo do hamoena, bahen ma djolmamoe na opat $\mathrm{i}$ bahen sidegean ni anakmi dohot boroemi dohot djolmamoena i, ro do i toe hoetamoe. Alai molo so olo hamoe, ra di hoetangkon do i!" boti ma didok ibotona i. „Olo ba, itong! anggo i, hoebahen pe sidegeanna siopat halak $i$; na hoerimpoe do na toetoe harpe dohot sipoesipoe ditoeboehon dibahen na hoebajangkon, hape late ni roha ni siopat halak do ahoe maranak 
marboroe. On pe da ba itong! djooe ma apami toe bagas on, asa hoeoemma djolo!" boti ma didok Radja i.

Djadi didjooe Si Boroe Boenga Pandan Matogoe ma toetoe: „Ro ho djolo toe bagas on, ale Radja Mebangebang!" boti ma ninna. „Aha di ahoe da, namboroe?” boti ma ninna apana i. „Adong do na hoedok, aloesi djolo amanta toe bagas on! naeng mangkatai hamoe! ba i ma ninna!” „Olo namboroe! a[i] ise adong amanta di bagas i? p. 203 sian dia i ro? ,amanta” nidokmi? Noengnga tarhona na sai balga ahoe, indadong adong amanta, ai na dioembang di ampang do ahoe dohot ibotongki, toeng toe beangan pe dainang sabat ni pambahen ni siopat halak do i! ai djolma do ditoeboehon dainang, disingkathon harpe!” boti ma didok Si Radja Mebangebang. „Olo ba, apang! anggo loengoen ni rohami, paroeasroeas toe amanta $i$, asala ro do ho toe bagas on!" boti ma didok namboroena i.

Djadi laho ma ibana toe bagas, hoendoel ma ibana toe djoeloeon. Ro ma amana i, pintor dihaol ma ibana. „Olo ba, amang Radja Mebangebang, adong do hape hangoloeanhoe, sai na hoeagam do ahoe na poenoe, hape adong do damang daon poenoe!" ba i ma ninna Radja i. „Olo, Radjanami, anakmoe pe ahoe didok ho, inda toeng damang dape ho dohonongkoe, ai so doeng ho hoeida ia so on!" boti ma didok anakna i. ,Olo amang! anggo loengoen ni rohami diparoeas ho toe ahoe, adong beha ningkoe? On pe beta ma hita toe hoetanta, anggo inam siopat halak i bahen sidegeanmoe pe itabahen!" boti ma ninna amana i. „Molo songon i apang, laho ma ho djolo moelak toe hoetanta, bahen ma djolmam na opat $\mathrm{i}$ bahen sidegeannami laho toe hoeta, sada ma bahen di harbangan $i$, sada di tonga ni alaman i, sada di djamboer i, sada di bona ni tangga i! boan ma dainang i toe hoeta on!" boti didok anakna i.

Djadi laho ma amana i moelak. Sahat ro di hoeta, bangkit ibana toe bagas. Doeng ni manoengkoen ma djolmana siopat halak: „Beha do djoedji, anak ni namboroe?” boti ma ninna nasida. „Olo ba, ,anak ni namboroe!" ninna boroe ni asoengkon! boroe ni bodathon! Anggo hamoe na opat bahenongkoe ma hamoe sidegean ni anakki dohot djolmangki dohot boroengki!" boti ma ninna. Djadi dipansarathon ma sian bagas, dipampagohon ma di tangga, dohot di djamboer, dohot di alaman, dohot di harbangan. Doeng ni ditopot ma Si Boroe Antar Roha: „Beta ma hita ale boroe ni datoelang! itairingkon 
p. 204 anakta i dohot boroenta i!” boti ma ninna Radja i. „Olo da, anak ni namboroe! molo adong anakta nimmoe, adong do dohonongkoe, alai sian dia ma adong anakkoe dohot boroengkoe? Atik adong i, beasa ahoe toe beangan?" boti ma ninna djolmana i. „Olo boroe ni Radjanami, anggo loengoen ni rohami diparoeas ho toe ahoe, adong beha ningkoe? Inda noengnga diahap boroe ni asoe i na hansit?" boti ma ninna. Djadi laho ma nasida.

Sahat ro di hoeta ni ibotona i, marhobas ma anakna i dohot boroena i, borhat ma nasida, diparboan ma masna i saloehoetna. Doeng ni sahat ma ro di hoetanasida i, i ma, siopat halak i, dibahen sidegeannasida. Doeng ni laho ma nasida toe bagas, dipasoeksoek ma masnasida i. Doeng ni diboeat sada horbo bahen haroannasida. Djadi gabe bolon ma nasida.

I ma soehoetan nasaingan sinoehoethon nannon.

\section{Vertaling.}

(blz. 189) Een verhaal uit lang vervlogen tijden ${ }^{1}$ ) vertelt van een daardoor beroemd geworden persoonlijkheid, genaamd Si Tadjom Bolak, die als een toppunt van dapperheid gold en uiterst rijk was. Hij woonde in het dorp Hoeta Silense Oetang en was gehuwd met $\mathrm{Si}$ Tondja di Portibi, een vrouw van bijzondere, onvergelijkelijke schoonheid.

Maar een jaar verliep, en $\operatorname{nog}^{2}$ ) vertoonde zij geen neiging een kind te baren.

Genoemde Radja dacht nu bij zichzelf : „Het is wel niet te verwachten, dat ik zoons en dochters krijg, als het maar bij deze eene vrouw blijft", en hij huwde toen nog Si Boroe Nan Sarindan van het dorp Hoeta Torop, dochter van een notabel man: Namora Pandji Meal.

Toen zij twee jaren bij hem was, bleek echter ook deze vrouw geen kinderen te zullen baren.

Hij trouwde toen opnieuw, maar ook nù kwam er geen kind ter wereld.

Daarop huwde hij Si Boroe Antar Roha, van Loemban Si Odjak, dochter van Radja Tinoempak.

1) nasaingan $=$ na sai ingan.

2) las soada $=$ laos soada. 
Toen deze zeven maanden bij hem was, verkeerde zij in blijde verwachting.

Tadjom Bolak ging nu op stap, achterlatende één schouderkleed, één broek, één baadje, één ring, één zwaard en één kippenei.

„Hier heb je”, aldus sprak hij, ,kleedij, bestemd voor hem, dien je in het moederlijf draagt; en wat betreft den vechthaan, waarover hij beschikken moet : dit ei laat ik (daartoe) voor hem achter! Wanneer dit ei later uitkomt, dan zal het iets buitengewoons ${ }^{3}$ ) opleveren! Welnu dan, ik ga voorloopig maar op stap; binnen zeven maanden kom ik wel weer van mijn tocht terug!"

„Wel, geliefde ${ }^{4}$ ), zoo zeide zijn vrouw, ,wanneer ge op stap gaat, best! Als ge binnen zeven maanden thuiskomt, dan vind ik het goed".

$\mathrm{Hij}$ vulde toen zijn tasch en vertrok naar het landschap Si Baragas, alwaar hij zich aan kansspelen ${ }^{5}$ ) overgaf. - En bij die kansspelen won hij steeds.

Toen hij drie maanden weg was, stond zijn vrouw op het punt te (blz. 190) baren. Si Boroe Antar Roha vroeg nu aan haar medevrouwen:

„Hoe gaat het bij een geboorte toe, waarde zusters?”

„Wel, zusje”, aldus haar drie medevrouwen, ,wat den gang van zaken bij het baren betreft, voorzoover wij dat meegemaakt hebben: men stopt van de barende vrouw de ooren dicht, dekt haar de oogen toe en bindt haar handen vast. Zoo gaat het, voor zoover wij dat althans meemaakten, bij een geboorte toe".

\footnotetext{
3) inda sibar = na so sibar.

4) „Anak ni namboroe” beteekent eigenlijk: „zoon van vader's zuster”, aldus noemt een vrouw haar geliefde of echtgenoot, ook wanneer deze niet in genoemde familiebetrekking tot haar staat. Op gelijke wijze wordt „boroe ni datoelang”, hetgeen eigenlijk beteekent: „dochter van moeder's broeder” gebezigd door iemand ten aanzien van zijn verloofde of vrouw, ook wanneer zij niet in e.g. betrekking tot hem staat. De woorden „namboroe” en „datoelang” worden verder resp. gebruikt in het aanspreken, resp. door een vrouw: van haar schoonmoeder, en door een man: van zijn schoonvader. Dit laatste, omdat het de gewoonte is bij voorkeur de dochter van zijn moeder's broeder tot vrouw te nemen (het z.g. ,cross-cousin-huwelijk”). (Vgl. noot 11, behoorende bij „Zeden, gewoonten en wetten van Nai Pospos", hierboven in de Inleiding genoemd).

5) Djoedji is, hoewel het allengs meer speciaal voor „dobbelen" wordt gebruikt, een algemeene benaming van vermaken, waarbij winstbejag komt, zooals weddenschappen, dobbelspel, het hanekloppen, enz. (vgl. v. d. T. blz. 212).

In casu moet er het houden van hanegevechten mede bedoeld zijn, aangezien het voortdurend winnen door $\mathrm{Si}$ Tadjom Bolak gedurende dezen tocht gezien moet worden als tegenstelling tot zijn - later - herhaaldelijk verliezen bij het hanevechten met zijn zoon.
} 
„Welaan dan zusters, als dat de regelen zijn bij het baren, naar ge meegemaakt hebt, handelt gijlieden dan zoo te mijnen opzichte; ik ben, geloof ik, nu zoo ver, dat de geboorte zal plaats hebben!" zoo sprak Si Boroe Antar Roha.

Metterdaad stopten zij haar nu de ooren dicht, dekten zij haar de oogen toe, en bonden zij haar de handen vast. Daarop vond de geboorte plaats van een jongen en een meisje.

De drie ${ }^{6}$ ) medevrouwen schoten nu dadelijk toe, en stopten de jonggeborenen in een rijstmand, waarin zij tevens deden de door $\mathrm{Si}$ Tadjom Bolak achtergelaten kleedij, alsook het kippenei. Vervolgens wierpen zij de mand in een groote rivier, zeggende: „Drijf, drijf ${ }^{7}$ ), waarde Radja Mebangebang! ${ }^{8}$ ) Wij hebben je medegegeven de kleeren, die door je vader achtergelaten werden, en ook het kippenei".

En zoo dreven zij beiden dan af.

Nadat de beide zuigelingen uit het gezicht verdwenen waren, keerden de vrouwen naar huis terug en legden zij in de plaats (van de jonggeborenen) een rotan pottenvoetstuk en een afgebrand stuk hout voor Si Antar Roha neer; daarop maakten zij haar oogbedekking los, alsook het touw, waarmede zij haar handen vastgebonden hadden, en namen zij haar de proppen uit de ooren.

Si Antar Roha keek nu vóór zich en zag het rotan pottenvoetstuk en het afgebrande stuk hout; zij vroeg toen aan haar medevrouwen:

„Zeg, waarde zusters, waar is nu hetgeen ik gebaard heb?”

Het antwoord van haar medevrouwen hierop was:

„Wel, waarom vraag je dat aan ons? Hondekind! Ongelukskraamvrouw, die geen ,moederlijf heeft” (= geen kinderen gebaard

6) Let wel op het woord "drie"; verderop toch wordt gerept van „vier", waarover ter plaatse meer.

7) „Maoep, maoep” is door v. d. Tuuk veranderd i.p.v. het sub-Tobasche "majoep, majoep".

8) Het woord mebang van de stam ebang - v. d. Tuuk (blz. 61) en Warneck geven „mangebang” - beteekent: ,zich opschikken om zich te laten zien, zooals na eene overwinning" (mebang een verkorte vorm, zooals er in het Bataksch vele voorkomen, parallel aan het Maleische „minta”, ,minoem”, ,milir”, ,moedik” enz., terwijl de verdubbeling van het grondwoord hier een voortduring of frequentie aangeeft).

Dat de door den geestelijken auteur voor den held van zijn verhaal gekozen naam Radja Mebangebang hiermede verband houdt, is zeker niet onwaarschijnlijk, waar Radja Mebangebang voortdurend alles overwint, en tenslotte ook over zijn stiefmoeders triomfeert. 
heeft) $!^{8^{a}}$ ) Een rotan pottenvoetstuk en een afgebrand stuk hout heb je gebaard! Je verdiende zelfs geen eten te hebben! Hondekind! (bl. 191) Apekind!"

En toen schopten zij met haar drieën ${ }^{6}$ ) Si Boroe Antar Roha.

Deze weende nu dag aan dag en nacht aan nacht.

De rijstmand kwam aan den oever bij Datoe Arang ni Begoe; en nu wilde het, dat zijn echtgenoote Si Tadjo Barang Holboeng naar de rivier was gegaan, en daar zag zij de rijstmand, rondtollende bij haar oever. Steeds wilde zij haar grijpen, maar ze kreeg haar niet te pakken; en Si Radja Mebangèbang en zijn zusje Si Boroe Ramiramian dreven verder af.

Maar nu verschijnt er een kraai, en deze begeeft zich in de mand; de kraai haalt vervolgens telkens wat schuim (van het water), en dat dient hij dan steeds aan Radja Mebangebang (en zijn zusje) als voedsel toe. Beiden groeien zij nu snel (als komkommers) op.

En dan gaat Radja Mebangebang naar het bosch, om rotan te halen ${ }^{9}$ ). Daar ontmoet hij een tijgerjong, hij vangt het, brengt het naar zijn hut, en fokt het tijgertje op. Het is al groot geworden.

\section{Dan zegt de kraai :}

„Hoor eens, lieve jongen ${ }^{10}$ ), Radja Mebangebang! wij moesten eens naar het dorp gaan van Vrouwe ${ }^{11}$ ) Nan Djoenggelè di Portibi, opdat wij daar eens vragen om het geweer Patanda Radja ${ }^{12}$ ), dat door Uw vader Si Tadjom Bolak daar in bewaring gegeven is; en verder om een dissel, een bijl met langen steel, een breede bijl, een beitel, een kapmes en een boor, opdat ge een schip kunt bouwen,

${ }^{8 n}$ ) Voorhoeve komt deze vertaling niet juist voor; hij acht deze moeilijke passage juister vertaald met: „Je tondi is er ontevreden over, geen zwangere buik meer te hebben (en heeft daarom deze misbaksels in de wereld gebracht)". Dit, wijl V. zich uit poestaha's de uitdrukking ,na boeragan toeboe" meent te herinneren als gezegd van een ongelukskind, d.i. ,hij die (of liever: wiens tondi) ontevreden is, omdat hij geboren is".

9) De verdubbeling van het grondwoord + si- bij deze werkwoordsvorm moet een verschrijving zijn, komt althans in geen der spraakkunsten voor.

10) Letterlijk: „lievelings-kleinkind”.

11) Letterlijk: Uw „Moeder".

12) bodil Patanda Radja: (v. d. T. blz. 434) $=$ bodil sanlotoes $=$ (v. d. T. blz. 477) één schot ter eere van een vorst; hier: = een geweer om er schoten mee te lossen ten teeken (tanda) van de komst van een vorst. 
waarmede we dan Uw Moeder Si Boroe Antar Roha kunnen opzoeken".

En zoo gingen zij dan naar het dorp van Nan Djoenggele di Portibi. Ze traden het dorp binnen en begaven zich voorts naar het huis van vrouwe Nan Djoenggele, waar Radja Mebangebang zich aan haar zijde neerzette. Vervolgens reikte Radja Mebangebang haar zijn tasch aan ${ }^{13}$ ), met de woorden:

„Bedient U zich van een betelpruimpje, tante!”

Vrouwe Nan Djoenggele schrok hiervan op, en zei:

„Wie zijt gij, mijn waarde, dat ge mij Uw tante noemt?”, waarop Radja Mebangebang antwoordde:

"Och, vrouwe, dat ik tante tegen $\mathrm{U} z e g$, is omdat men mij heeft (blz. 192) verteld, dat U een jongere zuster van mijn moeder zoudt zijn".

Zijn ,tante” antwoordde hierop: „Wel, mijn waarde! Wanneer ge een zoon van mijn zuster, van Si Antar Roha zijt, best! Maar wat komt ge dan wel in dit dorp doen?"

„Wel, vrouwe”, zeide hierop Radja Mebangebang, ,ik ben naar dit dorp gekomen, om de dingen te halen, die mijn vader $\mathrm{Si}$ Tadjom Bolak hier in bewaring heeft gegeven, dáárom kom ik hier".

„Nu, mijn waarde, wanneer $\mathrm{U}$ die dingen komt halen, in orde! Maar blijft U even zitten, ik zal wat eten koken", aldus zijn tante.

Zij ging nu eten koken, en schepte het, toen het gaar was, op een schotel, deed er een vingerkommetje bij en gaf dat aan haar "neef”, waarop deze het maal gebruikte. Toen hij klaar was met eten, ruimde zij op, en reikte zij hem vervolgens den betelzak aan. Si Radja Mebangebang bediende zich nu van een betelpruim, waarna hij het zakje retourneerde. Voorts bracht zij hem een slaapmatje, en legde hij zich te slapen.

Den volgenden dag slachtte zij een varken om er haar ,neef” op te onthalen. Zoodra het gaar was, noodde zij hem tot een gezamenlijk eten. Daarna gaf zij al hetgeen in bewaring gegeven was inderdaad aan hem af.

Hij nam nu afscheid van haar: „Dan ga ik maar weer, waarde tante!", zeide hij.

„Goed, mijn beste”, antwoordde zijn tante; en zoo vertrok hij; en hij kwam weer in zijn hut terug.

13) In den origineelen tekst stond: „disoerdoengkon"; v. d. T. wijzigde dit in ,disoerdoe $k$ kon". 
Zeven jaren, nadat zijn kinderen door de vier ${ }^{\mathbf{1 4}}$ ) stiefmoeders op het water geworpen waren, keerde Tadjom Bolak van zijn tocht terug. Zijn dienaren waren zwaar beladen met goud; en wel 120 slaven bracht hij mede, die hij met grof kansspel gewonnen had.

In het dorp aangekomen trof hij Si Boroe Antar Roha, - nog steeds in weemoed -, op haar plaats aan.

Zijn dienaren leverden er de medegebrachte schatten af.

De Radja vroeg daarop aan zijn vrouw : „Waar heb je onze kinderen gedaan? Ik liet je toch zwanger achter! Ik ben nu zelfs al zeven jaar weggeweest! ${ }^{15}$ ) Hoe staat het er mee? Ze zullen al wel groot geworden zijn!"

(blz. 193) „Wel, geliefde echtgenoot! wat Uw vraag betreft, het is juist, maar, beste echtvriend, mijn lot wijkt af ${ }^{\mathbf{1 6}}$ ) van dat van andere menschen, immers volgens mijn vier ${ }^{14}$ ) ,zusters” heb ik een rotan pottenvoetstuk en een afgebrand stuk hout gebaard".

„Zoo, vrouw! Als je dàt gebaard hebt, ga dan maar naar je familie terug! Je brengt me waarachtig door je lichamelijk gebrek $^{17}$ ) in opspraak!"

„Wel, heer en meester! Als $\mathrm{U}$ mij om die reden ${ }^{18}$ ) zoudt verstooten, best! Maar dat hebben zij maar gezegd! Ofschoon ik misschien toch werkelijk levende wezens heb gebaard! Ik heb ze niet gezien, ik heb ze niet gehoord, ik heb ze niet betast, (geen van die handelingen kon ik doen). Ik vroeg hen immers naar de in acht te nemen geboden bij het baren, en toen zeiden zij, dat de ooren moesten worden dichtgestopt, de oogen bedekt en de handen vastgebonden! En zoo bonden zij mijn handen vast, stopten zij mijn ooren dicht en bedekten zij mijn oogen!"

„Goed, vrouw! Als dat zoo is, laat ik je dan niet naar je familie terug brengen, maar ik zal je toch een jaar lang ${ }^{19}$ ) laten lijden!"

Hij haalde voorts de goederen weg, die zijn vrouw beheerde, en gaf ze aan de $\operatorname{vier}^{20}$ ) andere echtgenooten. Vervolgens ging hij slapen,

14) De auteur van het verhaal begint thans (vgl. noot 6) te bedenken, dat hij voor zijn slottafereel vier medevrouwen noodig heeft. Verzuimd is het begin van het verhaal daarmede in overeenstemming te brengen.

15) sagala = sanga (Tob. Bat. óók: „noenga sapola”).

16) Vgl. v. d. T. blz. 152 jo. 51 jo. 163.

17) Vgl. v. d. T. blz. 254.

18) "sabat" naar het Arabisch-Maleisch „sebab”, instede van ,ala".

19) intap $=$ sintap.

20) Wederom "vier" (zie noot 14), doch op deze plaats stònd in den tekst oorspronkelijk „drie”, hetgeen doorgehaald en door „vier" vervangen werd.

D1. 104. 
en wel in het huis van een van zijn andere vrouwen. Toen het weer dag was, sleepte hij Si Boroe Antar Roha uit het huis naar beneden, en sloot haar in de rijstschuur in het blok.

Dan verschijnt de kraai (weer), het dorp verkennende; en daar ziet hij dat Si Boroe Antar Roha naar de rijstschuur gebracht is en daar nog steeds in droefheid verzonken met gebogen hoofd (in het blok) $\mathrm{zit}^{21}$ ).

De kraai keert voorts naar de hut terug en deelt daar Si Radja Mebangebang mede: „Uw Moeder is in de groote rijstschuur in het blok gesloten!”

„Tja, oudje! Als Moeder dan in het blok gesloten is, wat is daaraan te doen? $\mathrm{Zij}$ moet dat leed voorloopig maar dragen; als haar Levens-Geest dat later zoo wil, wordt haar in eenzaamheid gedragen smart misschien wel gewroken", aldus Si Radja Mebangebang.

Hij ging nu een schip bouwen, waartoe hij een piras-boom ${ }^{22}$ ) omkapte. Toen deze neerstortte, rumoerden de rikrik-vogels, hetgeen door de kraai werd gehoord en deze deed uitroepen:

„Gagaoak! ${ }^{23}$ ) Hoe is het met U, Radja Mebangebang?”

Deze antwoordde: „Hier ben ik, oudje! De boom die ik aan het (blz. 194) kappen was is heusch niet op mij gevallen!"

„Wel, dierbare! Nu ik Uw stem heb gehoord, ben ik tevreden”, aldus de kraai.

Daarop mat Radja Mebangebang de lengte van zijn schip af, hij makte het vier vadem lang. En hij deed er zijn best op. Nadat hij er zeven dagen aan gewerkt had, was hij er mee klaar.

Vervolgens droogde hij het bij het vuur.

Daarna bracht hij het naar zijn hut.

Zeven dagen later voer hij weg naar het dorp van Namora Toenggoel.

Toen hij aan diens oever aangekomen was, schoot hij zijn geweer

21) „martoetoengkian” = mortoetoengkian (Toba Bat.) : v. d. Tuuk blz. 265. De reduplicatie van de eerste lettergreep van het grondwoord geeft een versterking aan; vgl. ook Marck's Bataksprache $\S 88$, die mortoetoengkian (niet geheel volledig) vertaalt met, sehr, tieftraurig sein".

22) = pirawas: v. d. T. blz. 348 ,zekere, geel stinkend timmerhout opleverende boom".

23) klank-nabootsend woord voor het krassen van een kraai, zie v. d. T. blz. 107. 
af, hief zijn vechthaan Patea Radja een gekraai aan en gromde zijn tijger Si Bolang (de gevlekte).

De waterdraagsters holden hard naar het dorp terug, waarop Namora Toenggoel vroeg:

„Waarom hollen jullie zoo, waterdraagsters? Wat gebeurt er?"

„Wel Radja, dat wij zoo hollen, dat is vanwege de aankomst aan gindschen oever van een prauwvaarder, die zijn geweer afschoot, terwijl zijn tijger een gegrom uitstiet en zijn haan aan het kraaien sloeg!"

Het Dorpshoofd maakte zich dadelijk op om te gaan, riep zijn bediende en begaf zich toen naar den oever om er poolshoogte te nemen; en daar zag hij inderdaad het schip, en hij vroeg: „Wie zijt gij, schipper, dat gij een geweer afschiet, terwijl Uw tijger gromt en Uw haan kraait, zoodat die vrouwen daar (de waterdraagsters) haar bamboekokers niet vullen kunnen?"

„Inderdaad, Vorst, ben ik dat geweest. Inderdaad schoot ik een geweer af, inderdaad gromde mijn tijger, en kraaide mijn haan. Maar wat diè daar betreft, die mij vergezelt, die heeft geen geluid voortgebracht!", aldus Si Radja Mebangebang.

„Dat zoo zijnde: wat komt U hier in mijn dorp doen?”

„Wel, Vorst, ik ben hierheen gekomen, omdat ik gehoord had, dat hier in dit dorp hanegevechten gehouden worden, waar het levendig toegaat; daarop afkomende kwam ik hier!"

„Nu dan, Radja, als $\mathrm{U}$ om die reden gekomen bent, dan zullen we morgen een hanegevecht houden; laten we nu beiden maar eerst gaan slapen", aldus Namora Toenggoel; waarop hij naar zijn dorp terugkeerde, en de waterdraagsters naar den oever zond, zeggende: „Gaan jullie maar naar de rivier. De tijger van onzen bezoeker doet niemand kwaad!"

(blz. 195) En de waterdraagsters gingen.

Den volgenden ochtend verliet Namora Toenggoel zijn huis, mede nemende zijn vechthaan Hoealam Radja, een op het midden van den rug zwarte, overigens geheel witte, haan ${ }^{24}$ ), zoomede 1400 (Realen?) als inzet. Hij begaf zich naar zijn oever en riep daar Si Radja Mebangebang op, zeggende: „Kom, Radja, we gaan een hanegevecht houden!"

24) In den tekst staat: „gonggom”, hetgeen een phonetische spelling is voor "gomgom", vgl. v. d. T. Wdb. blz. 119 en Spraakkunst blz. 10. 
„Goed, vorst”, aldus Radja Mebangebang, „laten we dat doen!” Hij stapte uit zijn schip en bond zijn haan de oogen toe. Ook Namora Toenggoel bond zijn haan de oogen toe. Zij zetten vervolgens elk 1400 in, en joegen hun hanen tegen elkaar op. Slechts éénmaal had de haan van Radja Mebangebang met zijn spoor achteruit geschopt ${ }^{25}$ ), of Namora Toenggoel had reeds verloren, immers zijn haan was dadelijk dood.

Si Radja Mebangebang nam de gelden op en bracht ze in zijn schip over.

Hierna begaf hij zich naar het dorp van Porhas Manoro. Aan diens oever aangekomen schoot hij zijn geweer Patanda Radja af, hief zijn tijger een gegrom aan en kraaide zijn haan. Geschrokken kwamen de dorpelingen naar den oever toehollen; daar zagen zij het schip van Si Radja Mebangebang aan den oever liggen, waarop zij, die waren komen kijken, de vraag stelden:

„Wie zijt gij, die een geweer afschoot, en wiens tijger zich deed hooren, wiens haan kraaide? Zoo lang als we leven ${ }^{26}$ ) heeft nog nooit iemand zich aan dezen oever op deze wijze aangemeld!" zoo zeiden zij.

„Wel, geachte lieden! Al knalde ook mijn geweer, al kraaide mijn haan en al deed mijn tijger zich hooren, hij zal nimmer menschen of vee kwaaddoen!" aldus Radja Mebangebang.

„Best, Radja! Maar met welk doel bent U naar onze oeverplaats gekomen?" (zoo sprak één hunner).

„Och, vadertje! Dat ik hierheen gekomen ben, dat is omdat ik gehoord heb over hanegevechten in dit dorp, die hun gelijke niet hebben in omvang; daarom kom ik in dit dorp een kijkje nemen", zoo sprak hij vanaf zijn schip.

„Wel, Radja, als U om die reden gekomen bent, dan zullen we morgenochtend hanegevechten houden! Wij keeren nu naar het dorp terug!", aldus de toegeloopen lieden. En daarop gingen zij naar hun dorp terug.

Hier ondervroeg hen het dorpshoofd Porhas Manoro:

"Wie is het, die daar aan den oever zijn geweer afschoot?"

„Wel, vorst, het is Radja Mebangebang, die gekomen is om, naar hij zegt, hanegevechten te houden!"

25) „tandak" = „schop”, etymologisch verwant met het Mal. „tendang”; in het Mandailingsch beteekent „tandak" : „hanespoor”; v. d. T. blz. 226.

$\left.{ }^{26}\right)$ lòlòt: in dit dialect evenals in het Mandailingsch voor "lèlèng". 


\section{„Als hij dat gezegd heeft, dat is best!"}

Daarop gingen zij ieder aan den maaltijd.

Toen het dag was, maakte hij zich gereed, gaf aan zijn bediende opdracht drie kisten goud mede te nemen, deed zijn versierselen aan

(blz. 196) en begaf zich voorts op weg, medenemende zijn vechthaan Hoeaso Padang.

Aan den oever aangekomen riep hij Si Radja Mebangebang op, zeggende: „Kom, waarde Radja, laten we gaan hanevechten!”

„Goed, vorst”, aldus Si Radja Mebangebang, ,ik kom! Om welke andere reden ben ik immers hierheen gekomen, ware het niet om een hanegevecht te houden?"

Voorts bonden zij hun hanen de oogen dicht; en toen dit gebeurd was, zetten zij ze tegen elkaar op: met één spoorslag door den haan van Radja Mebangebang was de haan van Porhas Manoro reeds gedood.

Si Radja Mebangebang nam de kisten met goud op en bergde ze in zijn schip.

„Luister eens, Radja Mebangebang!” zeide Radja Porhas Manoro, „ga nu nog niet weg, laten we morgen nog eens een hanegevecht houden!" En toen ging hij huiswaarts.

Den volgenden ochtend nam hij zijn vechthaan mee $\left.{ }^{27}\right)$. Hij kwam weer aan den oever, waarop zij beiden hun hanen de oogen toebonden en elk zijn inzet bekend maakte. Porhas Manoro zeide, dat zijn inzet was drie slaven, een dochter en drie stel bekkens (van vier stuks elk).

„Als ik van U verlies”, zoo zeide Porhas Manoro, „dan is dat alles, wat ik genoemd heb, voor U! Neem dan mijn dochter tot vrouw, maar U zult haar niet Uw slavin mogen noemen!"

Toen gingen zij tot het hanegevecht over. Porhas Manoro verloor, waarop Si Radja Mebangebang zeide:

„Haal Uw dochter en Uw slaven!”

Inderdaad ging hij toen zijn dochter en slaven halen.

„Kom, vrouwe Boroe Sori Naek”, zoo sprak Porhas Manoro (tot zijn dochter) ,ik breng U naar Uw gemaal!"

27) Het M.S. is hier wel zeer slordig; het eenige logische woord dat uit de combinatie van een vlekkerig ,di" en de letters $b$ o $a$ gevormd kan worden, is „diboan”. 
„Goed, vader, ik zal dan nu naar mijn echtgenoot toe moeten gaan, maar wiè is toch Uw schoonzoon?"

Hierop deelde hij het haar mede: „Radja Mebangebang is Uw gemaal".

„Wel, vadertje, als dat nu mijn echtgenoot is, best, vadertje”.

Daarop nam Porhas Manoro zijn dochter mede, alsook drie stel bekkens en drie slaven; deze gaf hij aan Si Radja Mebangebang af met de woorden: „Hier hebt ge mijn dochter, waarde schoonzoon!”

„Goed, schoonvader!" zeide Si Radja Mebangebang; en hij bracht haar in zijn schip, waarop hij dadelijk naar zijn hut terugkeerde.

Hier schoot hij zijn geweer af, hetgeen de kraai hoorde en deze zeggen deed:

"Gagaoak! Hoe is het met Uw hanegevechten gegaan, waarde Radja Mebangebang?"

(blz. 197) „Wel oudje, ik heb gewonnen! Ik heb een mooi ding gekregen: een meisje, om mij als vrouw te dienen in deze hut!' en hij ging (met haar) zijn hut binnen.

$\mathrm{Zijn}$ bedienden gelastte hij zijn schip en de bekkens te bewaken.

Voorts kookten zij eten: en gingen zij aan den maaltijd, waarna hij zich te slapen legde, tezamen met Si Boroe Sori Naek.

Toen het weer dag was, kookten zij rijst met visch, en gebruikten zij, zoodra een en ander gaar was, hun maal.

Hierna hing hij zijn bekkens op, en het geluid dier bekkens golfde gedurig uit; dan hield hij met het bespelen der bekkens weer op, en bracht ze in zijn schip terug.

Dan komt de gedachte bij Radja Mebangebang op: Laat ik eens naar mijn dorp terugkeeren, mijn moeder zal er al wel hoe langer hoe erger aan toe zijn in het blok!, zoo dacht hij bij zichzelf.

Zeven dagen later maakte hij zich op om te gaan:

„Zeg oudje, kom! we gaan naar het dorp van vader; al erger en erger zal moeder, door vader in het blok gezet, er wel aan toe zijn!” aldus Radja Mebangebang.

„Wel mijn beste!”, sprak de kraai, ,dat is uitstekend, laten we gaan!"

En zoo gingen zij dan, zij roeiden hun schip met pagaaien ${ }^{28}$ ) voort.

28) „borsi” v. d. T. Wdb. blz. 391, een korte roeiriem; op en om het Tobameer wordt dit woord steeds vervangen door ,hole”, eigenlijk de naam van een boom, van welks hout men zulke riemen maakt. 
Aangekomen aan den oever van Si Djangga Moera Meroe schoot hij zijn geweer af, hief zijn tijger een gegrom aan en kraaide zijn haan. Het dorp raakte in opschudding; en men kwam naar den oever, en ondervroeg den schipper:

„Wie zijt gij, dat ge een geweer afgeschoten hebt? Zoolang wij leven is er nog nimmer iemand aan onzen oever gekomen op een dergelijke wijze, met geweerschoten, met grommen van zijn tijger en kraaien van zijn haan!' zoo zeiden de toegeloopenen.

Hierop gaf Si Radja Mebangebang ten antwoord: „Och Radja, al knalde mijn geweer, al kraaide mijn haan en al gromde mijn tijger, hij zal geen menschen of vee kwaaddoen".

„Best Radja!”, aldus de toegeloopenen. „Wat is dan de reden, dat U naar onzen oever gekomen bent?"

„Wel, waarde lieden, dat ik naar Uwen oever gekomen ben dat is, omdat ik U een bezoek wilde brengen voor een hanegevecht".

„Als dat de reden is van Uw bezoek aan deze streek, dan zullen we daar even kennis van geven aan ons Hoofd, misschien wil hij het wel tegen U opnemen!", aldus de toegeloopenen.

Zij keerden daarop naar hun dorp terug.

(blz. 198) Het dorpshoofd vroeg hen daar: „Wie is het, die het geweerschot loste aan den oever?"

„Wel, vorst, Si Radja Mebangebang is hier op bezoek gekomen voor een hanegevecht, zegt hij".

„Goed, als hij daarvoor komt, in orde! Gaan jullie hem dan snel het volgende mededeelen: „De vorst laat zeggen, dat eerst morgen het hanegevecht tusschen U zal kunnen plaats vinden". Dat moeten jelui hem zeggen".

"Goed, vorst" zeiden ze, en ze gingen naar de oeverplaats terug, en riepen Si Radja Mebangebang aan, zeggende: „Hoort $U$ eens, Radja Mebangebang! De Vorst heeft gezegd, dat U niet weg moet gaan. Morgen zal het hanegevecht tusschen $U$ plaats kunnen vinden, zeide de vorst".

„Wel, waarde lieden, wanneer Uw vorst zegt, dat we het hanegevecht morgen zullen houden, in orde!", aldus Si Radja Mebangebang.

Zij keerden daarop naar hun dorp terug en een ieder legde zich te slapen.

Toen het weer dag was, maakte het dorpshoofd zich gereed. Aan zijn bediende droeg hij op, de geldkist te dragen. 
Vervolgens gaven zij zich over aan het hanegevecht; Si Djangga Moera Meroe verloor en Si Radja Mebangebang bracht zijn winst naar zijn schip over.

Hierop vertrok hij naar het dorp van zijn tante.

Aan de meerplaats van zijn tante aangekomen, legde hij zijn schip vast en schoot hij zijn geweer af, terwijl zijn tijger gromde en zijn haan kraaide.

Zijn tante kwam uit het dorp toesnellen, uitroepende:

„Wie zijt gij, die daar schoot, en zich aan mijn oever bevindt?”

De kraai antwoordde hierop: „Neem hem eens goed op, Boroe Boenga Pandan Matogoe! U bent beroemd om Uw kunst van waarzeggen! Profeteer nu eens!"

„Wel mijn waarde! Naar mij de teekenen zeggen lijkt hij mij de zoon van mijn broeder, Si Radja Mebangebang is zijn naam, zoo zegt mijn waarzegkunde; zijn echtgenoote zou deze eene vrouw zijn, Si Boroe Sori Naek zou haar naam zijn; en wat de andere vrouwspersoon betreft, dat is mijn nicht Si Boroe Ramiramian geheeten!", aldus Si Boroe Boenga Pandan Matogoe.

Dadelijk omhelsde nu Si Radja Mebangebang zijn tante en zeide: „Kom tante, gaat $U$ ons voor naar het dorp! Maar mocht mijn vader uit gindsch dorp hier komen, dan moogt ge mij niet aan hem bekend maken. Zoolang ik op die vier vrouwen van hem nog niet (blz. 199) met mijn voeten mag treden, en zoolang zij niet een voetveeg voor mijn moeder zullen zijn, en ook $U w$ nicht over hen zal loopen, zoolang wil ik niet naar zijn dorp toe!"

„Ach, mijn waarde, wel ${ }^{29}$ ) al hadt ge mij dat niet gezegd, zou ik het dan niet geweten hebben?" zoo zeide Tante.

Daarop gingen zij dorpwaarts.

In het dorp aangekomen schoot hij zijn geweer af, terwijl zijn tijger gromde en zijn haan kraaide. Een ieder verwonderde zich, toen ze den tijger zagen.

Si Radja Mebangebang bracht vervolgens al zijn zaken in de woning, waar zij zich voorts aan den maaltijd zetten. Na het maal herhaalde hij het schieten.

Si Tadjom Bolak vroeg zich toen af: „Wat gebeurt er toch ${ }^{\mathbf{3 0}}$ )

29) oea: v. d. T. blz. 58 (Oewa).

so) Oorspronkelijk stond er in den tekst oelaning; dit is veranderd in oelaing. Beide vormen komen voor. 
ginds in het dorp van mijn zuster, dat ze maar steeds een geweer afschieten?"

Toen het weer dag was, beval hij zijn vrouw om snel te koken. Zoodra het eten gaar was, at hij; en toen hij daarmede klaar was, stond hij op en begaf zich naar het dorp van zijn zuster, waar hij in de dorpspoort rondspiedde.

De bediende van Si Radja Mebangebang schoot nu weer het geweer af.

Si Radja Tadjom Bolak vroeg toen: „Wat is er hier in dit dorp toch te doen, dat gijlieden geweerschoten afgeeft?"

„Wel, vorst, dat wij geweerschoten afgeven, dat is omdat gisteravond een gast van den Radja hier aangekomen is, met een zwaar beladen schip, brengende hij ook met zich mede bekkens en slaven!", aldus de dorpsnotabele (Hoofd van de boroe-marga).

De vorst vroeg hierop: „Uit welk dorp is hij dan wel gekomen?” „Het is mij geenszins bekend, uit welk dorp!" antwoordde de notabele.

Si Tadjom Bolak begaf zich toen naar de woning van zijn zuster, waar hij zich aan haar zijde neerzette. Si Radja Mebangebang reikte hem daarop zijn tasch aan met de woorden : „Bedient $U$ zich van een betelpruim, waarde vorst!"

"Gaarne, vorst!, wanneer een collega mij den betel geeft, dan moet dat aanvaard worden! Maar mijn tasch is niet gevuld!", zoo sprak Si Tadjom Bolak.

„Wel, mijn vorst! Wanneer $U$ het niet hebt, dan kunnen we dit wellicht met elkaar deelen!" ${ }^{31}$ ), aldus Radja Mebangebang.

Si Tadjom Bolak bediende zich nu van een betelpruim, waarna hij de tasch retourneerde. Daarop stelde hij aan Si Radja Mebangebang de vraag: „Uit welk dorp komt U?”

„Wel vorst”, aldus Radja Mebangebang, ,de naam van mijn dorp (blz. 200) zou ik U niet kunnen mededeelen; volgens zeggen zou Tombak Siharangan (,Woud-en-Bosch") de naam van mijn dorp zijn!” "Wel, als dat dan de naam van Uw dorp is....?"

„Zoo is 't, o vorst! Maar den naam van mijn vader, noch den naam

31) Het gebruik wil nl. dat men onderling de beteltasch uit,,wisselt".

De Hr. Voorhoeve deelt mij nader mede, dat de Bataksche student Philip L. Tobing deze passage aldus zou willen vertalen: dat vereffenen wij weleens (n.l. een andere keer)". Dit acht ik inderdaad beter. 
van mijn moeder ken ik. Immers dadelijk na mijn geboorte zijn vader en moeder gestorven!"

Vervolgens vroeg de vorst aan zijn zuster:

„Zeg zuster, wie is hij? Naar het mij voorkomt is zijn schouderkleed gelijk aan het schouderkleed, dat ik destijds gekocht heb, en zoo lijkt me dat ook toe wat betreft zijn broek, zijn gordel en zijn hoofddoek!"

„Neen, broer, dat is een dochtersverwant van mij. Wat die dingen betreft, die U genoemd hebt, wellicht zien zij er als dezelfde uit!", zoo sprak Si Boroe Boenga Pandan Matogoe. Waarop ze het gesprek staakten.

„Dan ga ik eerst maar weer terug, zuster! Morgen zal ik weerkomen; ik verlaat me voor deze aangelegenheid op jou!", aldus de vorst.

"Goed broeder", zeide zijn zuster; waarop hij vertrok.

Toen hij in zijn dorp was aangekomen, vroegen hem zijn vier vrouwen:

„Wie is toch in het dorp van Uw zuster aangekomen, dat ze maar steeds een geweer afschieten?"

„Ik weet het niet met juistheid; ik vroeg hem naar den naam van zijn dorp: Tombak Siharangan (Woud-en-Bosch) noemde hij toen als naam daarvan; ik vroeg hem verder den naam van zijn vader en dien van zijn moeder, en die wist hij niet. Direct na zijn geboorte zouden volgens zijn zeggen zijn moeder en vader gestorven zijn. En toen ik naar zijn kleeding keek, zag ik, dat zijn schouderkleed geleek op dat, hetwelk ik achterliet ${ }^{32}$ ); daarop vroeg ik hem, hoe hij heette, en noemde hij Si Radja Mebangebang als zijn naam!”.

Hierop keken de vier vrouwen elkaar aan, en dachten gelijkelijk bij zichzelven :

„Dan is hij het, dien we vroeger eens weg hebben laten drijven”.

De vorst ging daarop naar beneden, en maakte Si Boroe Antar Roha uit het blok los.

32) In den tekst staat „hoetinggal”, waarmede bedoeld moet zijn „hoetinggalhon" daar "na hoetinggal" in het bijzonder zou beteekenen: ,hetgeen ik als erfenis naliet"; het hier en op andere plaatsen in dit verhaal gebezigde grondwoord is overigens in het geheel niet een Bataksch woord, doch Maleisch voor "(hoe) tading(kon)". 
(bz. 201) sluiten", zoo zeide zijn vrouw.

„Ge hebt er naar het schijnt genoeg van mij in het blok op te „Inderdaad! Ik deed dat om te kennen te geven, dat je mij te schande had gemaakt; precies een jaar heb ik je nu vastgezet", aldus de vorst.

Daarop ging zijn vrouw zich baden en schrobde zij het vastgekleefde vuil van zich af. $\mathrm{Na}$ het bad keerde zij naar het dorp terug.

Den volgenden dag slachtte de vorst een varken als zoenoffer voor zijn vrouw. Daarna begaf hij zich weer naar het dorp van zijn zuster. Hier stelde hij Si Radja Mebangebang de vraag:

„Wat zoekt gij eigenlijk in dit dorp, dat U hierheen deed komen?” „Wel vorst, ik ben naar dit dorp gekomen voor hanegevechten!” zoo sprak zijn zoon.

„Als dat zoo is, laten we dan een hanegevecht houden”, aldus de vorst.

„Uitstekend!” antwoordde zijn zoon.

En ze gingen tot hanevechten over; als inzet opgevende drieduizend elk.

De vorst verloor.

Hij gelastte zijn bediende geld te halen; en ze herhaalden het hanegevecht; wéér verloor de vorst.

„Luister eens, Radja Mebangebang”, zoo zeide hij, „Ga nog niet heen! Ik ga nu naar mijn dorp terug, maar morgen zullen we opnieuw hanegevechten houden".

„Goed vorst”, aldus zijn zoon, ,wanneer U ook maar zegt te willen komen voor een hanegevecht, U zult me bereid vinden!"

De vorst ging nu heen.

Toen hij in zijn dorp was aangekomen, vroegen hem zijn vier vrouwen:

„Hoe ging het met het hanevechten, geachte echtgenoot?”

„Och, geachte vrouwen! de gast van mijn zuster heeft mij met hanegevechten verslagen, maar morgen zal ik opnieuw een hanegevecht met hem houden!"

Des anderen daags slachtte hij een manoek Mira Sialtong (een roode haan, die boven den snavel een plek heeft van een geheel andere kleur) ter bereiding van een offermaal, om zich op de moeilijkheden van dien dag voor te bereiden. Daarop zette hij zich aan den disch, het maal aan zijn Levens-Geest opdragende met de woorden : „Waarde 
Levens-Geest! hoor mij aan! Gisteren verloor ${ }^{33}$ ) ik tweemalen met hanevechten, was ik telkens de verliezende; straks ga ik voor de derde keer; ach, waarde Levens-Geest! laat mij nu overwinnaar zijn!". En toen at hij.

Toen hij klaar was met eten, vulde zijn vrouw de tasch van haar echtgenoot. Hij riep nu zijn bediende en ging opweg, drie kisten medenemende voor zijn inzet. Voorts nam hij met zich een kris met (blz. 202) een geheel met goud beslagen scheede, en een gouden buikbandplaat.

In het dorp van zijn zuster aangekomen, zeide hij: „Kom, mijn waarde Radja Mebangebang, laten we gaan hanevechten!"

„Goed vorst”, aldus zijn zoon.

Daarop gingen ze hanevechten. Wederom verloor de vorst. Deze begaf zich toen in het huis van zijn zuster.

„Waarom komt $U$ hier binnen? Hoe is het met Uw hanegevecht gegaan?”, zoo sprak Si Boroe Boenga Pandan Matogoe.

„Ach zuster! Hij heeft me weer doen verliezen!"

„Wanneer hij U weer heeft doen verliezen, wat weet ge dan te bedenken, om dat geld voor U te verkrijgen?”, zoo zeide zijn zuster.

„Hoe zou ik nog kunnen denken?" antwoordde de vorst.

„Ach broeder! Ge hebt nu wel Si Antar Roha in het blok gesloten, maar zij heeft heelemaal geen rotan pottenvoetstuk en een afgebrand stuk hout gebaard, en het was slechts de naijver van die vier vrouwen over het feit, dat mijn schoonzuster ${ }^{34}$ ) een zoon en een dochter op haar schoot zou houden; zij hebben de jonggeborenen van mijn schoonzuster doen wegdrijven! - „Hier heb je de kleederen die je vader je achterliet en het kippenei, waarde Radja Mebangebang, en jij Boroe Rami Ramian!" - Zóó hebben die vier vrouwen toen gedaan. En nu, broeder! Wanneer ge het er mee eens bent, maak die vier vrouwen van $U$ dan tot voetveeg van Uwen zoon en Uwe dochter en Uwe vrouw, dan zal hij in Uw dorp komen! Maar, indien ge dat niet wilt, dan zal hij misschien wel hier in mijn dorp blijven", zoo sprak zijn zuster.

3s) In het M.S. staat na 2 doorgehaalde letters alleen „go", bedoeld moet hier zijn het in dit verband zeer goed passende "mago"; dan wel heeft hier een verschrijving plaats gehad, en moet er "do" gelezen worden, zoodat de vertaling Iuiden moet: „Gisteren heb ik twee malen een hanegevecht gehouden;” welke emendatie volgens den $\mathrm{Hr}$. L. Tobing beter is, omdat volgens hem "mago" in bovengenoemde beteekenis gebruikt een modernisme is.

34) eda, v. d. T. blz. 60 , i.c. $=$ broeder's vrouw. 
"Goed zuster! Wat dat betreft, ik zal die vier vrouwen tot hun voetveeg maken. Het was omdat ik dacht, dat zij werkelijk een rotan pottenvoetstuk en een afgebrand stuk hout gebaard had, dat ik haar in het blok sloot, en nu blijkt achteraf, dat het de naijver van die vier vrouwen was, omdat mij een zoon en een dochter gewerden. En nu, zuster! roep Uw neef hier in huis, opdat ik hem eerst omhelze!", aldus de vorst.

Metterdaad riep nu Si Boroe Boenga Pandan Matogoe hem, zeggende :

„Kom even binnen, waarde Radja Mebangebang!"

„Wat wilt U van mij, tante?” antwoordde haar neef.

„Ik heb $U$ wat te zeggen. Kom even binnen, om Uw vader te woord te staan. Gij hebt wat met elkaar te bespreken, zegt hij”.

(blz. 203) „Ja maar, tante. Welke vader van mij is dan binnen? Waar is hij vandaan gekomen? Mijn ,,vader” heeft U gezegd? Nu ben ik al zóó groot geworden, en ik heb nooit een vader gekend! Met mijn zusje hebben ze me doen afdrijven in een rijstmand, en Moeder werd door het toedoen van die vier vrouwen in het blok gesloten! Menschelijke wezens toch bracht Moeder ter wereld, en die hebben zij verwisseld met een rotan pottenvoetstuk!" zoo zeide Si Radja Mebangebang.

„Kom, neefje! Wanneer ge grieven hebt, lucht Uw hart dan bij Uw Vader, maar kom nu binnen!", aldus zijn tante.

Hij kwam daarop binnen en zette zich (zelfbewust ${ }^{35}$ ) neer op het hoogere gedeelte van den vloer.

Meteen komt zijn vader naar hem toe en omhelst hem, zeggende: „Wel, beste Radja Mebangebang! Nu kan ik dan toch nog mijn leven genieten (n.l. zonder vrees meer, kinderloos te moeten sterven) ${ }^{36}$ ); steeds dacht ik maar, dat ik kinderloos was, en nu zijt gij er, aan die kinderloosheid een eind makend! ${ }^{37}$ )"

35) „djoeloeon": het hooger gelegen gedeelte van den vloer van een huis (het tegenovergestelde van „djaëan"), dat als eereplaats beschouwd wordt (v. d. T. blz. 215).

36) In den tekst staat abusievelijk ,ado dong" in plaats van "adong do" (... hape hangoloeanhoe). Het hier door Si Tadjom Bolak gezegde had ik gedacht ook te kunnen vertalen met: „nu heb ik dan achteraf toch kinderen”, zulks in verband met de uitdrukkingen ,adong do hangoloeanna” en ",morhangoloean" van vrouwen gezegd die in blijde verwachting zijn: ,hangoloean” hierbij op te vatten als ,leven" = „levend wezen” = een „kind”.(?) De Heer Ph. L. Tobing vat deze uitlating op als: „(nu heb ik dan toch) een bestaan, iemand die mijn leven zal voortzetten, waarop mijn leven rust".

${ }^{37}$ ) Dit is een zeer gelukkige verbetering van Voorhoeve, die op een andere groepeeringsmogelijkheid van de letters $d$ a $o$ n $p$ o e n $o_{e} e$ wees, waaruit ik 
„Wel vorst! $\mathrm{Al}$ noemt $\mathrm{U}$ mij ook $\mathrm{Uw}$ zoon, ik zal $\mathrm{U}$ toch nog niet Vader noemen, immers ik heb U nooit eerder gezien dan nu pas!"

„Ach mijn beste! Wanneer je zoo de bekommernis van je hart voor mij uitstort, wat zal ik dan zeggen! Kom laten wij naar ons dorp gaan. Die vier stiefmoeders van je zal ik je tot voetveeg maken!”

„Wanneer $U$ er zoo over denkt, vader, gaat $U$ dan éérst naar ons dorp terug, en laat die vier vrouwen ons tot voetveeg dienen, wanneer wij in het dorp komen. Zet er één neer in de dorpspoort, één midden op het dorpsplein, één vlak vóór het huis bij de rijstblokken, één aan den voet van de huistrap! En breng Moeder naar dit dorp!", zoo zeide zijn zoon.

De vader keerde nu terug. In zijn dorp aangekomen, trad hij zijn huis binnen. De vier vrouwen vroegen hem: „Hoe is het met het hanevechten gegaan, geëerde echtgenoot?"

„Ja, ja! „geëerde echtgenoot" zeggen deze hondekinderen, deze apekinderen! Jullie vieren zal ik tot voetveeg maken van mijn zoon en mijn vrouw en mijn dochter!", zoo antwoordde hij.

En toen sleepte hij ze de woning uit en groef ze tot haar schouders in den grond ${ }^{38}$ ), bij de trap, bij de rijstblokken, op het dorpsplein en in de dorpspoort. Voorts zocht hij Si Boroe Antar Roha en zeide tot haar: „Kom, laten we gaan, geliefde echtgenoote! Laten we onzen zoon en onze dochter halen".

(blz. 204) „Wel, geëerde echtgenoot! Wanneer U zegt, dat wij kinderen ${ }^{39}$ ) hebben, dan moet ik het wel beamen, maar hoe zou ik aan een zoon en een dochter komen? Mochten zij er zijn, waarom werd ik dan in het blok gezet?"

„Ach, geëerde vrouwe, wanneer ge zoo Uw kommer tegen mij lucht, wat zal ik dan zeggen? Gevoelen die hondekinderen zich al niet ellendig?", zoo zeide hij.

En toen gingen zij.

drie woordjes distilleerde, (zoodoende komende op de vertaling: „zeg eens, ben ik dan kinderloos?"), terwijl hier kennelijk bedoeld zijn de twee woorden „daon poenoe" = geneesmiddel tegen kinderloosheid. Vgl. „daon sihol” Spr. blz. 398, en Warneck).

38) Letterlijk: „heide ze in".

39) Strikt genomen makkt de tekst hier slechts melding van een ,zoon”, het woord ,anak" moet hier echter in het verband van het verhaal wel met "kinderen" worden vertaald. 
Toen zij in het dorp van de zuster van $\mathrm{Si}$ Tadjom Bolak waren aangekomen, makten hun zoon en dochter zich gereed, en vertrokken zij, al hun goud met zich medenemende.

In hun dorp aangekomen trapten zij op de vier vrouwen als voetveeg.

Ze traden vervolgens het huis binnen, en stapelden daar hun goud in hoopen op. En ze slachtten een buffel tot het aanrichten van een feestmaal.

En ze werden rijk gezegend ${ }^{40}$ ).

Dat is het onderwerp van het verhaal uit oude tijden, thans hier verteld.

Rijswijk (Z.-H.), eind October 1944.

\section{NASCHRIFT.}

Dr. P. Voorhoeve, in de Inleiding reeds genoemd als auteur van de ,Volksverhalen der Bataks", sinds die publicatie werkzaam geweest in de functie van „Ambtenaar voor de beoefening van de Indische talen", en die vóór Wereldoorlog II nog gedurende iets langer dan drie jaren in de Noord-Oostelijke Bataklanden vertoefd heeft, om er het Simaloengoen-Bataksch te bestudeeren, kwam vorig jaar in patria terug en is thans Conservator van de Oostersche handschriften aan de Rijksuniversiteit te Leiden.

Hem, specialist op het gebied van de oude Bataksche literatuur, werd het bovengegeven verhaal, vóór het ter perse ging, voor een critische beoordeeling terhandgesteld.

De door den $\mathrm{Hr}$. V. bereidwillig op zich genomen examinatie, gevolgd door een nauwgezette bespreking van de materie, heeft tot resultaat gehad, dat de niet duidelijke tekstgedeelten op een paar plaatsen door een andere lettergroepeering gepaard met een andere klemtoonlegging juister weergegeven konden worden.

Hem komt voor de hierdoor verkregen philologische verbeteringen dank toe.

Met den Hr. V. werden ook besproken twee punten die van groot

40) „gabe bolon"; óók: schatrijk; ik heb het hier in de alles omvattende beteekenis genomen, omdat zegen voor den Batak vooral inhoudt het hebben van veel kinderen, hoewel de aanhef van het verhaal er op schijnt te wijzen, dat hier meer aan geldelijke rijkdom gedacht is. 
belang zijn ter fine van een uniforme verwerking van Bataksche handschriften, n.l.:

1e. de woordscheiding;

2e. de spelling.

Het gaat er n.l. om:

of, wat het eerste punt betreft, de nadrukswijzers ,do" en „ma”, naar voorbeeld van de Maleische aequivalenten "lah" en „poen” en de Mal. vraagpartikels „kah” en „tah”, verbonden moeten worden aan de daaraanvoorafgaande woorden, waarop zij betrekking hebben,

danwel, in navolging van bijv. de Grieksche encliticae $\pi \varepsilon \varrho, \tau \varepsilon$, $\gamma \varepsilon, \delta \varepsilon$, die in de uitspraak toch ook vastverbonden zijn aan de woorden waarop zij haar functie uitoefenen, nochtans los daarvan geschreven worden;

en wat het tweede punt aangaat: of met het oog op de klankverandering van sommige letters of lettercombinaties bij agglutineering de oude Bataksche schrijfwijze moet worden gevolgd, danwel een phonetische spelling toegepast, - alsdan echter ook voor de grondwoorden - zooals door Van der Tuuk in de eerste geschreven stukken van zijn hand en in de inhoudsopgaven van de diverse deelen der manuscriptenverzameling.

Op dit punt bestond n.l. geen uniformiteit: zoo schreef, om één voorbeeld te noemen:

de Bataksche schrijver van het hier behandelde verhaal (zie o.a. pag. 195 r. 38, pag. 197 r. 4, pag. 198 r. 14) ; ,didongkon”,

Van der Tuuk in zijn niet geheel doorgevoerde correcties (zie pag. 193 r. 29, pag. 194 r. 34) „mandokkon” en ,didokkon”,

Warneck in zijn Woordenboek: „mandokhon”.

Hierover behoeft nu echter niet langer te worden uitgeweid; aangezien volgens Voorhoeve inmiddels in overleg met de Zending een uniforme schrijfwijze vastgesteld werd, in hoofdzaak overeenkomstig die, welke door de Zending reeds sinds lange jaren gebezigd werd. Dit lag dan ook wel voor de hand, waar zij met haar School- en Kerkelijke boekjes en andere geschriften het meeste gepubliceerd, en met haar methode reeds school gemaakt heeft.

N.a.v. zijn ,stiefmoederlijke behandeling” van Si Radja Mebangebang in zijn meergenoemde publicatie „Overzicht van de Volksverhalen der Bataks" zal de Hr. V. hieronder nog het een en ander te berde brengen.

Ook zal de Hr. V. na zijn epiloog over Si Radja Mebangebang geven een lijst van corrigenda op het in het vorige deel gepubliceerde 
artikel „Zeden, gewoonten en wetten van Nai Pospos”, aangezien hij ook de tekst dáárvan met het origineel vergeleken heeft, en daarin nog andere fouten heeft ontdekt, dan de vele drukfouten, die anders uiteraard door mijzelf ter correctie zouden zijn opgegeven.

Die andere fouten, te wijten aan onjuiste transcriptie of interpunctie, vielen buiten mijn gezichtsveld, omreden, behalve voorzoover betreft de in de Inleiding bedoelde enkele bladzijden en regels, benevens de zinnen, waarin Vergouwen vraagteekens plaatste, de tekst van Vergouwen's copie door mij niet getoetst werd aan het origineel. In den tijd n.l. dat ik het door Vergouwen aangevangen werk voortzette kon ik over het betreffende manuscript niet vrijelijk beschikken, omdat het met het oog op bominslag en brandgevaar niet „uit huis" mocht, doch na raadpleging weer veilig in de kluis moest worden opgeborgen, terwijl ikzelf (als Repetitor voor Leidsche en Utrechtsche onderduikers) evenmin veilig was.

De Hr. Voorhoeve heeft nu echter in het belang der wetenschap de gelegenheid te baat genomen om de geheele materie aan de hand van het origineel door te nemen, teneinde den aan de verwerking daarvan door Vergouwen en mij gepraesteerden arbeid ook philologisch te vervolmaken.

's-Gravenhage, 31 Mei 1947.

\section{NASCHRIFT}

door Dr. P. Voorhoeve.

Ik heb iets goed te maken tegenover de arme $\mathrm{Si}$ Boroe Ramiramian. Haar naam heb ik verdonkeremaand, evenals die van haar broer, en anoniem heb ik haar één moment ten tonele gevoerd in de valse rol van het zusje van haar eigen vader in die ongelukkige drie regels op blz. 161 van mijn proefschrift ${ }^{\mathbf{1}}$ ). En zij voelde zich toch al lang niet op haar gemak in de Bataklanden. Weggedoken in een hoekje van haar broers prauw gaf ze geen kik als het geweer lustig pafte, de tijger vervaarlijk gromde en de haan helder kraaide. En toch was zij eens de heldin van het verhaal, een verre, heel verre verwante van de Atjèhse prinses Goudkruintje, van Straparola's Serena en van Parizade uit het verhaal der jaloerse zusters in de Duizend en één Nacht van Galland.

1) Overzicht van de volksverhalen der Bataks. Vlissingen 1927.

D1. 104. 
Een Batakse verteller heeft haar geschiedenis gehoord, toen hij eens uit zijn bergen naar Baroes was gekomen om zijn benzoë te verkopen en inkopen te doen van zaken, die zijn eigen land niet opleverde. Van de rondzwervende Maleise zeevaarders hoorde hij dit verhaal 's avonds in de kedai, een geschiedenis, zoals er zoveel de ronde deden in die zeemanskringen.

Maar het verhaal van de jaloerse stiefmoeders en de verworpen tweelingen heeft bij de Bataks geen ingang gevonden. Daarvoor deed het hen te veel denken aan de onheilspellende mythe van de oorsprong van de Batakse priesterstaf, ontstaan door het incest van een tweelingbroer en zuster. Slechts kort heeft het in de Batakse volksoverlevering geleefd; wie weet of niet dezelfde Batak, die het van een zeevaarder hoorde, het heeft opgeschreven ${ }^{2}$ ) voor dien vreemden Hollandsen kedai-houder, die alles wat goedkoper verkocht dan zijn concurrenten om maar klanten te trekken, met wie hij kon praten; en die nog betaalde ook voor het opschrijven van zulke sprookjes.

Het lijdt echter geen twijfel, dat de verteller zich de geschiedenis voorstelt als spelende in een Batakse omgeving. Alle personen dragen Batakse namen, in tegenstelling met een Mandailingse versie, die later werd opgetekend ${ }^{3}$ ); daar herinnert de naam Poetiri Santan Batapis nog direct aan Minangkabause oorsprong. Daarom verdient dit verhaal uit Baroes toch wel een plaats in een overzicht van de volksverhalen der Bataks, èn een uitgave, bijna een eeuw nadat het werd op schrift gesteld!

Mejuffrouw M. C. H. Amshoff heeft, toen zij in haar proefschrift ${ }^{4}$ ) de Atjèhse Hikajat Goemba' Meuih behandelde en allerlei varianten uit Europa, Afrika en Azië vergeleek, wel het Mandailingse verhaal „Pardosir Dijapari” in haar onderzoek betrokken, maar „Si

2) De gissing van den heer De Boer, dat dit Goeroe Tinandangan uit Nai Pospos is geweest, is wel zeer waarschijnlijk wegens overeenkomst van taal en spelling met stellig door hem geschreven stukken, maar twijfel blijft mogelijk, daar Cod. Or. 3405 in het net geschreven verhalen bevat, die van verschillende auteurs zouden kunnen zijn. Van het eerste dier verhalen, Si Malin Deman, bestaat ook een exemplaar op boombast geschreven (in het Indisch Instituut, no. A 4171). De "handtekening” van Goeroe Tinandang(an), door den heer De Boer vermeld, heb ik ook met zijn hulp niet terug kunnen vinden. De naam luidt duidelijk Tinandangan op de eerste blz. van Cod. Or. 3397.

3) Pardosir Dijapari, mijn Overzicht no. 167, uit de collectie Van Ophuysen.

4) Goudkruintje. Een Atjèhsche roman met vertolking en toelichting. Leiden 1929. 
Tadjom Bolak" niet als een variant van hetzelfde verhaal herkend ${ }^{5}$ ). De varianten zijn door haar ingedeeld in vier groepen. Het begin van de Atjèhse roman rekent zij, evenals het daarvan overigens zeer verschillende Mandailingse verhaal, tot de 1001 nacht-groep ${ }^{6}$ ). Het verhaal van Si Tadjom Bolak en Si Radja Mebang-ebang moet stellig tot de vierde, Indisch-Indonesische groep gerekend worden, en is daarvan een tamelijk zuivere representant ${ }^{7}$ ). Ook uit dit oogpunt beschouwd is het een uitgave alleszins waard.

\section{ERRATA}

in het artikel: Zeden, Gewoonten en Wetten van Nai Pospos (Bijdr. 103, blz. 399 evv.).

Wijlen Vergouwen had zich tijdens zijn verblijf in de Bataklanden wel op de taal, maar niet op het Batakse schrift toegelegd. De begonnen copie, transcriptie en vertaling zijn door hem na terugkomst in Holland gemaakt, terwijl hij het schrift nog niet volkomen beheerste. De heer De Boer, die het stuk in oorlogstijd bewerkte, had toen geen gelegenheid, om de gehele tekst met het handschrift te vergelijken. Daardoor was het mogelijk, dat er in de copie fouten werden gemaakt, die weer de oorzaak waren van fouten in de transcriptie, deels ook in de vertaling. De resultaten van een vergelijking met het handschrift worden hieronder medegedeeld; tevens worden daarbij enige drukfouten verbeterd.

Inleiding: p. 341 r. 1 zou wel een bezoek hebben gebracht 1 . heeft wel een bezoek gebracht; p. 342 r. 24 Nadiengien 1. Madiengien.

Tekst: p. 346 r. 7 mahoemansoep 1. ma hoemansas (voor hoemashas); r. 8 telaga 1. talaga; r. 10 holoetoe 1 . holoe toe; r. 13 en $17 \mathrm{i}$; ba, na 1 . ibana; r. 14 e.e. noenga of noengga 1. noengnga; r. 15 oenang 1. inang; r. 21 hasibasoonsa di 1 . hasibasoon sadi; r. 24 e.e. doengi 1. doeng $n i$; r. 33 toe sipoesok 1. toesi poesok; p. 347 r. 5 ibana 1 . na; r. 20 goarni i, masitili- 1 . goar ni, i ma sitili-; r. 29 panganan 1.

5) Hoewel het door J. de Vries vermeld was in zijn aantekening op no. 116 van zijn Volksverhalen uit Oost-Indië (deel II, Zutphen 1928 blz. 365). Ook de twee daar genoemde Soendase varianten heeft Mej. Amshoff niet gebruikt.

6) t.a.p. blz. 215 .

7) Veel punten van aanraking heeft het met het bij de Bataks wèl tamelijk verbreide verhaal van Si Boroe Soerat Moelia Gading (Overzicht no. 162) 
panganon; r. 33 toeng 1. noeng; r. 39 dana $k$ 1. danahon; p. 348 r. 3 hierbij een aanteekening van Van der Tuuk: „Deze plegtigheid heet ook patoetoe aeèkkon"; r. 5 disi 1 . asa disi; r. 8 parindahanan 1 . parindahanan $i$; r. 19 poegoe 1 . pogoe; r. 31 komma achter ma

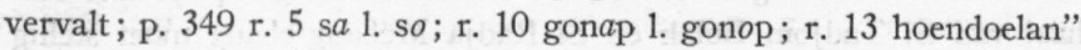
na 1. hoendoelanna"; r. 24 het woord ni (ook na?) is in het hs. doorgestreept; r. $30 \mathrm{i}$ boeloe is wel een verschrijving voor boeloe i; p. 350 r. 16-17 1. Molo nadong bahenon ni soehoet, na balga ma diboeat haroanna, mangkoeling gondang ma dibahen; p. 351 r. 9 sipanarbangi 1. sipanorbangi; r. 12 hoepang i 1 . hoepangi; p. 352 r. 17 dipoedini 1 . di poedi ni; r. 19 diroea $h$ 1. di roea $k$; r. 32 dipasa $h 1$. dipasak; p. 353 r. 6 i, ba, na 1. ibana; r. 21 impas 1. timpas; p. 354 r. 9 toe 1. ro ma; r. 28 nasa tingting 1. satingting; r. 29 satarnapoeran 1. $\mathrm{sa}[\mathrm{n}] \mathrm{ta} p$ napoeran; p. 355 r. 14 halak mangoli 1 . halak $n a$ mangoli; r. 17 arian 1. arianna; r. 27 Doeng 1. Doeng poengoe; p. 356 r. 1-3 1. „Boti ma i, hamoena soehoet $i ! \ldots$ ia na boeangon ompak ni ngingi ni anakmon, asa binoto; hape molo na djoroton, asa hoeboto!"; r. 7 ambihoel 1. tambihoel ; r. 13 na mardaoep 1. simardaoep; r. 21 sitoboesonna 1. sitoboeson ni soehoet (door v. d. T. ingelascht); r. $25 n a 1 . i$; r. 27 hapoer 1 . hapoer mahiang; r. 32 toroe 1 . toroe $n i$; p. 357 r. 6 oeli 1. $n a$ oeli; r. 9 idaidaon 1. idaidaan; r. 18 sahalak 1. ma halak; r. 29/30 1. mangalompai ma naposo boroeboroe, mangalompai inkajoe ma naposo lahilahi, deba paoeli babi; soen masak....; p. 358 r. 1 achter manoek in het hs. ingevoegd: datoe morboan; r. 4 na di 1 . di; sapa 1 . sira; r. 21 vóór Doeng in te voegen: Doeng soen dibagihon laho ma halak midjoer; r. 33 toe tordangan 1 . na toe ordangon ; r. 35 masitatadjomi ordang $a$ n 1. masitadjomi ordang$n a$; p. 359 r. 28 marsitolong 1. masitolong; r. 33 dohot ma 1. dohot; p. 360 r. 11 martoea 1. na martoea; p. 362 r. 2 handang 1. handangna; r. 8 sahoeta 1 . hoeta; r. 10 dahanon 1 . dahanon $n a$; r. 18 na sada 1 . nasida; p. 363 r. 21 mombangpoea 1 . mombang doea; r. 22 manoek na 1. manoek sada; r. 30 hinoenihon beide malen 1. hinoenihan; p. 364 r. 22 ondjapindjap 1 . ondjapondjap; r. 32 dakdanak ma 1. dakdanak$n a$; r. $33 / 34$ laho, toe simaroetang 1 . laho toesi, maroetang; p. 365 r. 2 rombadan 1. rombajan; r. 5 na oebaton 1 . nioebatan; r. 7/8 mortoedjoe-toedjoe 1 . mortoedjoeng-toedjoeng; p. 366 r. 7 ditortor 1 . ditortorhon; r. 18 nipi na 1. nipina; r. 19 gabean 1. gabet; p. 367 r. $25 / 26$ saloehoet i moet vervallen; p. 368 r. 6 babi $n a$ haroanna 1. babi haroanna; r. 33 mamboan 1. marboan; p. 369 r. 6 vóór sitompion in te $v$.: nitak dohot bahen; r. 13 marhobas 1 . na marhobas; r. 21 
nasitaroep 1. $n i$ sitaroep; r. 28 bahenonna 1. bahenon $n i$; p. 370 r. 23 dahanan 1. dahanon; r. 30 indahan indang 1. indadong; r. 33 mamake 1. mamahe; p. 371 r. 2 vóór margondang in te $v$.: doeng ni; r. 13 schrap het eerste ditortorhon; r. 18 soemoen 1. soemoendoet; ti $n$ djak 1. tidjak; p. 372 r. 35 hobas 1 . hohas; p. 373 r. 15 loboe 1. lamboeng; r. 30 en 31 dibangki 1. dibangkai; p. 375 r. 4 lahililahi 1. lahilahi; p. 376 r. 17 degeonna 1. degeon ni; p. 377 r. 1 gaol, zoo in het hs. verbeterd voor pisang; r. 8 schrap: na so tarhaol begoe sahoendoelan; r. 26 disisikki : „oeloebalang” 1. „Si Sikki Oeloebalang”; r. 34 sangatoepan, (er stáát: saatoepan); r. 38 boetoehana 1. diboetoehei ma; p. 378 r. 11 oelaon 1. oelaonna; r. 15 marsage 1. marsahe; r. 28-35 de interpunctie is onjuist; r. 34 moet na siling doea nog eer keer doea ingevoegd worden, terwijl het eerste doea op r. 35 moet vervallen. Wschl. te lezen: boeloeng ni tabartabar pitoe, boehoena pitoe; boeloeng ni sibalihangin pitoe; boehoena pitoe; boeloeng ni andoelpak pitoe; boehoena pitoe; boeloeng ni sisangkil pitoe, boehoena pitoe; boeloeng ni sipilit pitoe, boehoena pitoe; boeloeng ni sipalis pitoe, boehoena pitoe; boeloeng ni siroengkas pitoe, boehoena pitoe; boeloeng ni sibabolhas pitoe; boehoena pitoe; boeloeng ni langge sihoek doea; boeloeng ni silingdoea doea; boeloeng ni bira siarang doea. p. 379 r. 2 achter dipaoeli is in het hs. ingevoegd: datoe i; r. 4 siling doea, zo in het hs. veranderd voor het (wschl. juiste) silindoea; r. 5 achter: pinardjolma in te v. : ma; r. 7/8 molo.... dibahen te schrappen; r. 17 1. na hatioeran $n a$ gorakgorahan; r. 33/34 schrap de herhaling; p. 380 r. 12 hadangan 1. angkadangan; r. 20/21 di siharoear 1. disi haroear; r. 26 pardoepaan 1. pardaoepaan; r. 32 vóór dipasaor in te v.: doeng soen na doea hali; r. $32 \mathrm{Na}$ te schrappen; r. 36 dibagasan 1. dibogasan; p. 381 r. 1 pargagaran 1. parpagaran; r. 17 Onggoeng 1. Tonggoeng; p. 382 r. 8 soehoet 1 . sahoeta; r. 13 simargogo 1 . simargonggom; r. 17 rangkaproengk $a \mathrm{p}$ 1. rangkaproengkoep; r. 19/20 omboeloena 1. imboeloena; r. 23 poeloengan 1. poeloengpoeloengan; r. 29 schrap de herhaling ; r. 34 djoempok 1. djoemompok; p. 383 r. $8 / 9$ martondoeng 1 . martondong; r. 19 sahoeta 1 . na sahoeta.

Vertaling: p. 384 r. $8 / 9$ (en .... zal) 1. op het punt om te bevallen; $12-141$. Verder moet er aan de horizontale middenbalk van het huis bast van de toropboom vastgebonden worden, opdat deze kan dienen om er zich aan vast te houden voor de barende vrouw ; r. 20-22 1. „Wel, moeder”, aldus de heer des huizes, „dat ik u mijn betel gegeven heb, is omdat ik u omtrent de ziekte van mijn vrouw hier wil raadplegen; r. 28-30 en van hen hooren enz. 1. deugdelijk en 
juist moge steeds blijken de kunde die zij aan mij hebben overgebracht; p. 385 r. $1 / 2$ 1. zij den vader.... is, laat zij het door een kind; r. 7/8 legt die onder den navelstreng 1 . drukt den navelstreng er tegen; p. 386 r. 4 daarnevens een betelpruim in schuitsgewijs gevormd betelblad 1. een bovenheupstuk; r. 5/6 een pijp van bamboe .... tabak 1 . een vlerkgewricht; r. $22 / 23$ vrouw'sverwant.... is 1 . dochtersverwanten het meisje niet koopen kunnen; p. 387 r. 21 1. een kind met een schoonen naam; r. 35-37 doet hij dat.... vleeschmaal 1. moet hij een groot beest slachten voor de naamgeving van zijn zoon of dochter; p. 388 r. 4 waarmede hij de rijstzak vaststeekt 1 . die hij in de rijst steekt; r. 32-34 Iemand .... peet is; deze verklaring wordt inderdaad door $v$. d. T. gegeven s.v. roro voor toelang roro bot; wellicht moet echter gelezen worden: toelangna ro, ro bot en vertaald: een oom van den jonggeborene....; tegen het vallen van den avond .... ; p. 389 r. 28 te veranderen als het begin van hoofdst. 3 en het woord ,rijst” te schrappen; p. 392 r. $4 / 5$ wij .... worden 1. wij komen kunnen om de bruid te halen; p. 393 r. $1 / 2$ en hangt.... schenken wschl.: en steekt er zijn mes tusschen; p. 394 r. 17-38 is een moeilijke passage. Vergouwen heeft vroeger (Adatrechtb. 35 blz. 139) tandoek ni mas verklaard als ,aandeel, dat de naaste verwanten en aanverwanten van den parboroe bekomen”. De hier gegeven verklaring van tandoek ni mas als ,wezenlijke waarde van de bruidschat" berust op het woordenboek van v. d. T. blz. 227: „,de wezentlijke waarde van gouden sieraden”. Waarschijnlijk is Vergouwen's vroegere verklaring juist, en wordt hier bedoeld, dat bij de berekening van die aan de verwanten en aanverwanten van den parboroe te betalen bedragen voor gouden sieraden een speciale waardeering geldt. Een andere moeilijkheid is, dat de beteekenis van de uitdrukking oembarbar goendoerna niet bekend is; de in noot 31 hiervan gegeven verklaring kan onmogelijk juist zijn. Er moet mee bedoeld zijn een of andere tegenprestatie van den paramaan en den amangoeda in geval zij iets meer krijgen dan het hun minimaal toekomende. In de vertaling moet in ieder geval verbeterd worden: informeert hij naar 1. vordert hij; en verderop: als het aandeel van dien oom van vaderskant zóó groot is, dan ,bekapt hij zijn pompoen”; krijgt hij echter 6 realen met als 7de een zijdwapen, dan is dat voor hem nog geen aanleiding om ,zijn pompoen te bekappen”. Voorts wordt als aandeel van den jongeren broer van den vader één binsang gegeven; krijgt hij 2 binsang, dan ,bekapt hij zijn pompoen”; is zijn aandeel één binsang, dan houdt hij zich stil (d.w.z. dan is hij tevreden 
gesteld, zonder echter tot een tegenprestatie verplicht te zijn); p. 397 r. 24 maar te meer vrees hebben 1 . wel eens een scheet kunnen laten tijdens de plechtigheid; p. 398 r. 10-12 opdat .... zeggen 1. dat ik het wete; of zal ik ze „binden”, dat ik het wete (mandjorot is blijkbaar óók een technische term); p. 400 r. 33/34 die dienen.... kippeneieren 1. de offerberas en de kippeneieren draagt de datoe; r, 37 houten bakje met 1 . zout en de; p. 401 r. 1 opspuit 1 . neervalt; r. 22 vlg.: lees de eerste keer i.p.v. zaaiers: „menschen”, de tweede en derde keer ,pootgatenmakers"; p. 403 r. 7 individueelen strijd 1. strijd tegen vreemden; r. 9 evv. 1.: wanneer de oorlog echter gevoerd wordt binnen de federatie, dan mag men geen versleten rijststamper toepassen. Tot het bewerken van den rijststamper (wanneer men dien wel toepast, dus in een oorlog tegen vreemden) geeft men opdracht aan een deskundige; p. 404 r. 11 e.e. geroosterd 1. de veeren afgebrand; p. 405 begin hfdst. 11 te 1 . Even groot als het voorbereidingsmaal is het heiningloon; p. 406 laatste gedeelte van hoofdstuk 12 1.: Is de strijd beslecht, dan wordt, wanneer zij boete ontvangen, dat wat geacht wordt den schuldenaar toe te komen, met zijn schuld verrekend. Maar vervallen zij in boete, dan moet die eerder betaald worden dan de verschuldigde collectieve bijdrage. p. 408 r. 11/12 een groot offerschaaltje dat kunstig gevlochten is 1 . twee groote of ferschaaltjes; p. 409 r. 18 klanken 1 . bovenrand; r. 19 door mij afgedekt 1. daar op het altaar; p. 410 r. 4 kip 1. groote oude haan; p. 412 r. $23 / 24$ Nadat.... hebben 1 . Tegen het aanbreken van den dag; p. 414 r. 15 de vertaling: legt men dat alles op onderleggers is alleen mogelijk, wanneer men in den tekst het woord toe invoegt vóór panganan; p. 415 r. 18 nog drie nachten lang 1 . drie nachten later; p. 416 r. 30/31 De verwanten.... tegenprestatie 1 . Aan zijn verwanten van vrouwskant schenkt hij dan elk één dollar als ,,vervanging van een mes"; p. 418 r. 16/17 Komt mij zoo snel mogelijk te hulp 1. Van geslacht op geslacht is het overgegaan tot op mij toe. r. 26 eeren 1. oprichten; r. 29 1. pidong ramboe marsada; p. 424 r. 15 hetgeen naar zijn deskundig inzicht verboden moet worden 1 . de verbodsbepalingen die met zijn kunde samenhangen (wier overtreding zijn offer krachteloos zou maken); p. 426 r. 8 schrap ,en sist hem weg”; Si Singki Oeloebalang is de naam van de parsili, zie bijv. poestaha Indisch Instituut A 4152 f ; r. 34 evv. zie de verbetering bij p. 386; op p. 427 de vertaling van de opsomming der verschillende planten te verbeteren naar de veranderde interpunctie in de tekst; p. 432 r. 20 evv. hamer 1. aambeeld; r. 24 mede 1. op; r. 27 maken 1. vullen; p. 433 
r. 33 de offerspijzen op de offerschotels 1 . de offerschotels op de korven.

Commentaar: Als gevolg van de veranderingen in tekst en vertaling moeten de nooten $7,31,59,86,111,121,148$ en 153 vervallen. Noot 136 is m.i. onjuist (de combinatie van saem en sita-sita komt n.1. vaak in poestaha's voor). Noot 159-161 langge is Homalomena alba Hassk.; langge sihock zal daarvan wel een variëteit of een der andere Homalomena-soorten zijn; silingdoea of silindoea is dan Homalomena rubescens Kunth. (vgl. Filet, Plantkundig woordenboek 2de dr. no. 7899 silong-doewa). bira is Alocasia macrorhiza Schott.; bira siarang waarschijnlijk de in het Maleisch birah hitam genoemde variëteit. 